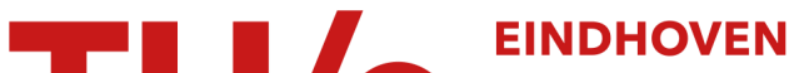 \\ UNIVERSITY OF \\ TECHNOLOGY
}

\section{The mechanism of ethylene epoxidation}

Citation for published version (APA):

Santen, van, R. A., \& Kuipers, H. P. C. E. (1987). The mechanism of ethylene epoxidation. Advances in Catalysis, 35, 265-321. https://doi.org/10.1016/S0360-0564(08)60095-4

DOI:

10.1016/S0360-0564(08)60095-4

Document status and date:

Published: 01/01/1987

\section{Document Version:}

Publisher's PDF, also known as Version of Record (includes final page, issue and volume numbers)

\section{Please check the document version of this publication:}

- A submitted manuscript is the version of the article upon submission and before peer-review. There can be important differences between the submitted version and the official published version of record. People interested in the research are advised to contact the author for the final version of the publication, or visit the $\mathrm{DOI}$ to the publisher's website.

- The final author version and the galley proof are versions of the publication after peer review.

- The final published version features the final layout of the paper including the volume, issue and page numbers.

Link to publication

\section{General rights}

Copyright and moral rights for the publications made accessible in the public portal are retained by the authors and/or other copyright owners and it is a condition of accessing publications that users recognise and abide by the legal requirements associated with these rights.

- Users may download and print one copy of any publication from the public portal for the purpose of private study or research.

- You may not further distribute the material or use it for any profit-making activity or commercial gain

- You may freely distribute the URL identifying the publication in the public portal.

If the publication is distributed under the terms of Article 25fa of the Dutch Copyright Act, indicated by the "Taverne" license above, please follow below link for the End User Agreement:

www.tue.nl/taverne

Take down policy

If you believe that this document breaches copyright please contact us at:

openaccess@tue.nl

providing details and we will investigate your claim. 


\title{
The Mechanism of Ethylene Epoxidation
}

\author{
R. A. VAN SANTEN AND H. P. C. E. KUIPERS \\ Koninklijke/Shell-Laboratorium, Amsterdam \\ Shell Research B.V. \\ Badhuisweg 3, Postbus 3003 \\ 1003 AA Amsterdam, The Netherlands
}

\section{Introduction}

The production of ethylene epoxide (EO) from ethylene by catalytic oxidation has grown into a worldwide industry, based on processes developed mostly in the 1940s and 1950 s $(1,1 a-c)$. With a view to reducing ethylene consumption, research has been continued to further improve the catalyst and optimize the process conditions. As a result, ethylene is currently converted with a selectivity of around $80 \%$ under commercial conditions, whereas in the early 1960 s the selectivity was $68 \%$ at a comparable conversion level.

Significant changes have been introduced in catalyst preparation as well as in catalyst composition. The catalyst consists of reduced silver particles dispersed on $\alpha-\mathrm{Al}_{2} \mathrm{O}_{3}$. The catalyst surface area has been increased by a factor of 5 , and in consequence the operation temperature has declined considerably. The use of chlorine compounds as moderators has been known since 1942 from the patent by Law and Chitwood (2). Since the carly 1970s alkali has been added to the catalyst as a promoter (3).

In view of these changes, the conclusions from early work on the relative rates of the reactions, occurring in the familiar kinetic scheme (Scheme 1) of epoxidation (1) may have to be modified for modern catalysts.

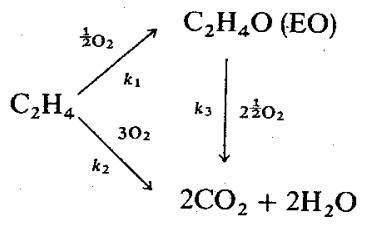

SCHEME 1 
However, few data on these catalysts are available in the open literature.

Scheme 1 can be used to illustrate two crucial mechanistic questions that dominate ethylene epoxidation research: first, which factors determine the initial selectivity at low conversion, governed by the ratio $k_{1} / k_{2}$, and second, what is the rate-limiting step of ethylene epoxide conversion $\left(k_{3}\right)$ that is important at high conversion?

Figure $1(1 b)$ illustrates the dependence of the selectivity on conversion for a nonpromoted catalyst in the absence of chlorine. Measurements of the selectivity versus conversion on chlorine-moderated catalysts of high initial selectivity have been published recently by Bryce-Smith et al. (Ic). Their results, presented in Fig. 2, indicate a strong decline of the selectivity at low conversion; at conversions higher than $10 \%$ the selectivity behaves as expected on the basis of Scheme 1.

It is generally accepted that the ratio of the parallel reaction rates $\left(k_{1} / k_{2}\right)$ is determined by interaction of ethylene and oxygen with the silver surface; by contrast, no agreement exists on the role of catalyst support versus the role of silver in the consecutive reaction, with rate constant $k_{3}$. Some authors propose (4) that the catalyst support does not play a direct role in the consecutive reaction and that ethylene epoxide is oxidized by silver. Twigg $(5,5 a)$ and others $(5 b)$ suggest that ethylene oxide first has to isomerize to acetaldehyde. Woodward et al. $(5 c)$ propose that ethylene epoxide is isomerized to acetaldehyde by acidic support sites and that acetaldehyde is oxidized in a consecutive reaction by silver. There is even a dispute on the latter question, since it has also been found $(6,6 a-8)$ that ethylene epoxide can be isomerized to acetaldehyde by silver.

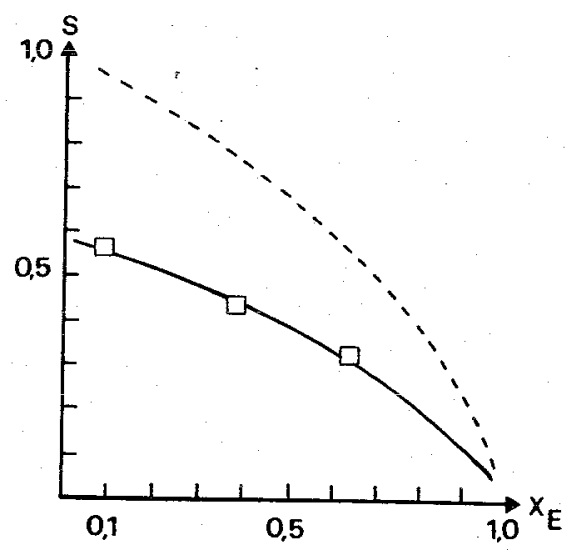

FIG. 1. Selectivity versus conversion. $T=523 \mathrm{~K} ;(---)$, expected dependence of $S$ on $X_{\mathrm{E}}$, conversion in the case of pure consecutive reaction; $8 \% \mathrm{Ag}$, pumice support, $1.6-2 \mathrm{~m}^{2} / \mathrm{g}(1 \mathrm{~b})$. 


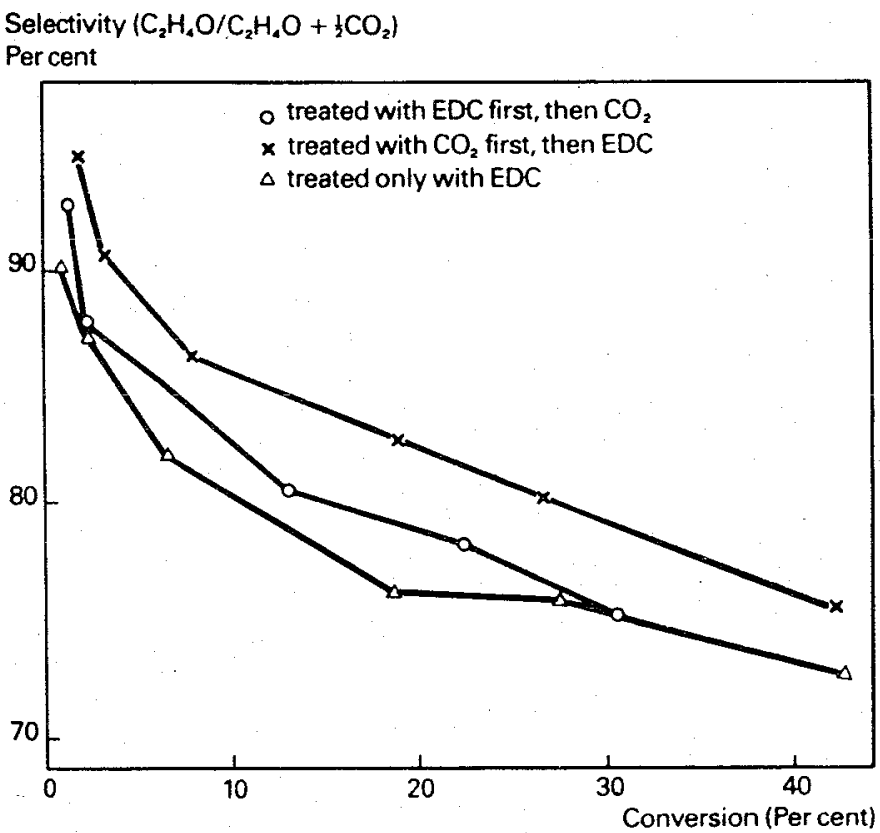

FIG. 2. Selectivity versus conversion. $4.75 \% \mathrm{Ag}, \quad 0.013 \% \quad \mathrm{Li}, \quad \alpha-\mathrm{Al}_{2} \mathrm{O}_{3} ; \quad \mathrm{EDC}=$ 1,2-dichloroethane (Ic); $5 \%$ ethylene in air; $160^{\circ} \mathrm{C}<T<235^{\circ} \mathrm{C}$.

Whereas it has been generally accepted that the initial selectivity of the epoxidation reaction is determined by the silver part of the catalyst, the details of the ethylene epoxidation mechanism and ethylene combustion mechanism are still controversial, notwithstanding many detailed and extensive investigations which have been reported in several review papers $(9-12,12 a, 13)$.

However, during the past decade significant advances have been made in the understanding of the reactivity of the silver-metal surface, mostly because of the impact of modern surface science techniques that enable the reactivity of silver single-crystal surfaces to be studied under well-defined conditions. In addition, a wide body of literature has become available on the interaction of oxygen, chlorine, alkali, carbon dioxide, and adsorbed organic molecules with such silver crystal surfaces.

We will discuss the two mechanistic issues in ethylene epoxidation in the light of new information gained from the use of these surface scientific techniques. It appears that the initial selectivity of ethylene epoxidation is governed by the state of oxygen adsorbed on silver. In the rate-limiting step ethylene is found to react with adsorbed oxygen $(14-19,14 a, 16 a)$. In the past three decades many investigations have been undertaken to establish the 
conditions the oxygen-silver system has to satisfy to yield epoxide. It has been thought for a long time that the ratio of atomically adsorbed versus molecular oxygen determines $k_{1} / k_{2}$. The role ascribed to both species has changed through the years. Twigg (5) and Hayes (20) proposed that isolated atomic oxygen is responsible for epoxidation, whereas pairs of adsorbed oxygen atoms are responsible for total oxidation of ethylene, via formaldehyde formation. Their arguments were based on the observation that the rate of the total combustion reaction is higher order in oxygen than the rate of ethylene epoxidation. German and Russian workers $(21 a-c, 22)$ proposed that molecularly adsorbed oxygen yields epoxide, whereas atomic oxygen gives total oxidation upon reaction with ethylene. The original idea is ascribed to Worbs (21). Kilty et al. (23) strongly supported this mechanism, on the basis of infrared adsorption studies that confirmed earlier work by Gerei et al. (24) and a study of oxygen adsorption as a function of chlorine coverage on silver catalysts.

The epoxidation mechanism by adsorbed molecular oxygen found wide acceptance, because it predicts a maximum selectivity of $6 / 7$. Only recently selectivities higher than $6 / 7$ have been reported $(1 c, 25)$. Ayame et al. (26) reported initial selectivities of $97-99 \%$ on silver catalysts doped with $\mathrm{NaCl}$. The net selectivity turned out to be $<80 \%$, since carbonaceous residue was formed on the catalyst, which was slowly converted to $\mathrm{CO}_{2}$ and $\mathrm{H}_{2} \mathrm{O}$. Recent research has significantly clarified the question of whether it is molecular or atomic oxygen that plays a role in ethylene epoxidation. Therefore, in view of this question, we will discuss in the next two sections the chemisorption of oxygen on silver and the reactivity of oxygen adsorbed to the silver surface.

In the section on chemisorption information is presented on the state of oxygen adsorbed onto silver surfaces. A compilation is given of the body of literature generated by surface science studies of single crystal faces of silver. A discussion of the coadsorption of alkali metals with oxygen is included in view of their presence in practical catalysts.

In the section on the reactivity of the silver surface we will concern ourselves not only with the reactivity of ethylene, but also with that of epoxide and acetaldehyde, molecules that play a dominant role in the consecutive reaction of ethylene epoxide. As we will show, coadsorption to the silver surface of ethylene oxide and of intermediates formed by consecutive reactions, or coadsorption of $\mathrm{CO}_{2}$ and $\mathrm{H}_{2} \mathrm{O}(17,27,27 a-c, 28,28 a-c)$, has a significant influence on the activity as well as selectivity of the reaction.

In a final discussion we will return to the question of the mechanism of ethylene epoxidation. There are still several unanswered questions concerning the transition state. However, as the review of current evidence will show, the oxygen species that is inserted into ethylene to give epoxide is most probably atomic in nature. 


\section{The Characterization of Oxygen-Containing Adsorbates on Silver by Surface Science}

Because the reaction probability for ethylene oxide production is very low (of the order of $10^{-8}$ ), the direct study of the reaction of ethylene and oxygen as a function of surface composition under ultrahigh-vacuum (UHV) conditions is precluded. One way out is the approach chosen by e.g., Campbell and Paffett $(29,30)$ and Grant and Lambert $(31)$. It comprises a two-step analysis. The catalytic behavior of a single-crystal face is studied in a highpressure reaction cell, in which measurable amounts of ethylene oxide can be produced. Subsequently, the reactants are pumped off rapidly and the sample is transferred within roughly $20 \mathrm{~s}$ to a UHV cell where it is subjected to surface analysis. Although this technique has been of great help in providing a detailed insight into ethylene oxidation, a principal drawback remains, namely that during pump-off and transfer, surface changes might occur unnoticed.

Numerous surface science investigations have been performed on silver surfaces to examine their behavior with respect to species relevant to ethylene oxidation. The following discussion will center on the silver/oxygen system. The coadsorption of other species such as alkali metals and chlorine will be discussed only insofar as they modify the oxygen speciation and behavior. The reason for this is that under ethylene oxidation conditions pure alkali metal adsorbates do not exist. For these single-phase systems the reader is referred to the references mentioned in the text.

\section{A. SPeciation of Oxygen on Silver by SURface SPECTROSCOPIC TeCHNIQUES}

A great many surface science studies have focused on the question of which reactive oxygen species leads to epoxidation. Three types of oxygen have been observed, namely molecular, atomic, and subsurface oxygen. Since a molecular adsorption state is the first step for an oxygen molecule approaching the surface, it will be dealt with first.

\section{Molecular Oxygen on Silver}

Adsorbed molecular oxygen is characterized by an oxygen-oxygen bond. Therefore the natural choice for its identification and characterization is a surface-sensitive vibrational technique. In 1980 Backx et al. (32) used highresolution electron energy loss spectroscopy (HREELS) for the identification and characterization of molecular oxygen on the low-index (110) plane of silver for the first time. However, molecular oxygen had been identified on 
supported silver long before, for instance by electron paramagnetic resonance (EPR) $(33,34)$ and infrared spectroscopy (35). According to Backx et al., molecular oxygen on $\mathrm{Ag}(110)$ is a weakly bound species, easily. desorbing or dissociating into two atoms above $170 \mathrm{~K}$. With respect to HREELS it is characterized (to $\pm 1 \mathrm{MeV}$, independent of coverage) by two peaks at 30 and $78 \mathrm{meV}$, attributed to oxygen-metal and oxygen-oxygen vibrations, respectively. The proof for molecular oxygen to be truly chemisorbed is given by the fact that a saturation coverage of atomic oxygen prior to oxygen adsorption at $110 \mathrm{~K}$ precluded the detection of any molecularly adsorbed state, showing that there is a major difference in "first-" and "second-layer" adsorption potential. Independent proof for the molecular nature of the weakly adsorbed oxygen was gained via temperature-programmed desorption experiments with a mixture of ${ }^{16} \mathrm{O}_{2}$ and ${ }^{18} \mathrm{O}_{2}$ by the same authors. The oxygen molecules desorbing at $170 \mathrm{~K}$ after dosing at $110 \mathrm{~K}$ did not show any scrambling, i.e., only the peaks at 32 and 36 amu showed up, whereas scrambling did occur for the fraction having dissociated at $170 \mathrm{~K}$ and ending up in the high-temperature peak at $580 \mathrm{~K}$. As regards the nature of the molecularly adsorbed state of oxygen, Backx et al. concluded the adsorption state to be of $C_{2 v}$ symmetry because any lower symmetry would have given rise to more than two peaks. The model proposed was an $\mathrm{O}_{2}$ molecule lying flat in the grooves of the (110) surface. A comparison of the low oxygen-oxygen stretching vibration at $78 \mathrm{meV}$ with those of other molecular oxygen reference compounds of varying formal charge $\left(\mathrm{O}_{2}^{+}, \mathrm{O}_{2}\right.$, and $\left.\mathrm{O}_{2}^{-}\right)$was used to extrapolate to a formal charge of $\mathrm{O}_{2}^{1.7-}$ for molecularly adsorbed oxygen, ascribed to back-donation of electrons from the metal to the $\pi^{*}$ antibonding orbitals.

Barteau and Madix (36) scrutinized the molecularly adsorbed state of oxygen on $\mathrm{Ag}(110)$ by adsorption and thermal desorption experiments including ${ }^{18} \mathrm{O}_{2}$ and ${ }^{16} \mathrm{O}_{2}$ isotope techniques. Although the gross features of their study closely matched those of Backx's work, there were conflicting results as regards the behavior of molecular oxygen during low-temperature $(\sim 120-130 \mathrm{~K})$ adsorption. Contrary to Backx, who could not detect any dissociation of oxygen during adsorption at $100 \mathrm{~K}$ [proven by the absence of a 39-meV energy-loss spectroscopy (ELS) peak, indicative of atomic oxygen], Barteau and Madix found that sequential filling of atomically and molecularly adsorbed states took place during adsorption. Although they had no direct spectroscopic evidence at their disposal, sequential oxygen-isotope dosing experiments showed clearly that oxygen was more likely to fall into the atomically adsorbed state at low coverage than at high coverage. Further evidence was based on their previous work on the reaction of formaldehyde (37) and carbon dioxide (38) with atomic oxygen, which yielded formate and carbonate species at $123 \mathrm{~K}$. 
The attempts of Barteau et al. to determine the activation energy for desorption of molecular oxygen gave widely varying results, depending on the method. Heating rate variation studies revealed an activation energy for desorption of $19.5 \mathrm{~kJ} / \mathrm{mol}$ with a first-order preexponential factor of $1.65 \times$ $10^{5} \mathrm{~s}^{-1}$. A simple Arrhenius plot yielded $28.7 \mathrm{~kJ} / \mathrm{mol}$ for the activation energy. Finally, the Redhead method with an assumed preexponential factor of $10^{13} \mathrm{~s}^{-1}$ gave a value of $46 \mathrm{~kJ} / \mathrm{mol}$. These variations were attributed to the competition with oxygen dissociation, in accordance with Backx et al. (32), who later pointed out that these attempts would yield the activation energy for dissociation of molecular oxygen rather than its activation energy for desorption anyhow.

Low-energy electron diffraction (LEED) investigations of the lowtemperature oxygen states did not show any ordering, indicating that both molecular oxygen and atomic oxygen formed from it were randomly distributed at low temperatures.

Campbell and Paffett (30) studied molecular oxygen on $\mathrm{Ag}(110)$ by X-ray photoelectron spectroscopy (XPS) and found it to give a single peak at $529.3 \mathrm{eV}$ binding energy with a full width at half maximum (FWHM) of $1.5 \mathrm{eV}$. In accordance with the work of Backx et al. (32), they also found that little if any dissociation of molecular oxygen occurs at $130 \mathrm{~K}$. The single oxygen peak for molecular oxygen led Campbell et al., too, to the conclusion that the oxygen molecule lies flat on the surface, since "end-on adsorption" would have produced two $\mathrm{O}(1 s)$ photoelectron peaks.

Au et al. (39) had previously postulated an $\mathrm{O}(1 \mathrm{~s})$ binding energy of $532 \mathrm{eV}$ to be characteristic of molecularly adsorbed oxygen on $\mathrm{Ag}(110)$. As their lowtemperature adsorption had been performed at low oxygen pressures with very long exposure times, which increases the risk of reactive water being adsorbed from the background by the surface oxygen, Campbell and Paffett (30) rejected their assignment. He based his argument on the findings of Stuve et al. (40) and himself that long exposures turn the adsorbate layer predominantly to carbonate and hydroxyl species. Moreover, he cited the same authors (39) with their previous assignment of $532 \mathrm{eV}$ to the hydroxyl group.

Campbell's photoelectron spectroscopic assignments are based on the complementary performance of thermal desorption experiments. Therefore his work sheds some doubt on a number of previous assignments, and hence also on conclusions drawn from coadsorption studies with alkali metals.

Prince and Bradshaw (4l) studied the valence region of molecularly adsorbed oxygen by ultraviolet photoelectron spectroscopy (UPS) at normal emission. They found peaks at $1.1 \mathrm{eV}$ (weak), $3.6 \mathrm{eV}$ (whose determination by difference spectra is hampered by the fact that it falls into the low-binding energy region of the silver $d$-band), $5.6 \mathrm{eV}$ (nonspecific for molecular oxygen because of its assignment to the "umklapp" process, i.e., to electrons having 
been ejected in an off-normal direction and elastically backscattered into the normal direction), and $8.6 \mathrm{eV}$ (weak and broad) below the Fermi edge. The center of the weak peak found at $3.6 \mathrm{eV}$ with $\mathrm{He}(\mathrm{I})$ was corrected to a value of $4.3 \mathrm{eV}$ by use of $\mathrm{He}(\mathrm{II})$ radiation.

The interpretation of the peaks was hampered by the absence of cluster calculation results for the molecularly adsorbed state at that time. Their assignment was therefore based on qualitative arguments starting from the $C_{2 v}$ symmetry proposed by Backx et al (32) and the previous assignment made by Spitzer and Lüth (42) for the $\mathrm{O}_{2} / \mathrm{Cu}$ system.

The 1.1-eV peak was tentatively assigned to a completely filled doublet level of $a_{2}+b_{1}$ symmetry derived from the gas-phase oxygen $1 \pi_{\mathrm{g}}$ orbital whose degeneracy upon adsorption was diminished far enough to turn the oxygen molecule to a singlet state. The corresponding lower level of $a_{1}+b_{1}$ symmetry was then identified with the peak at 3.6 to $4.3 \mathrm{eV}$. It should be mentioned that this assignment implies an $\mathrm{O}_{2}^{2-}$-type molecular oxygen, because the $a_{2}+b_{1}$ state falls below the Fermi level and hence is completely filled. Finally, the peak at $8.3 \mathrm{eV}$ was assigned to an oxygen level as well, being derived from the $3 \sigma_{\mathrm{g}}$ level of gas-phase oxygen which upon adsorption changed to $a_{1}$ symmetry. This assignment was claimed to be capable of explaining the enormous shift in vibrational frequency of the oxygen-oxygen band. The filling of the antibonding $3 \sigma_{\mathrm{u}}$ level for explaining this strong shift, as proposed by Sexton and Madix (43), was rejected as unlikely, because in the gas phase this level is about $9 \mathrm{eV}$ higher than $1 \pi_{\mathrm{g}}$, although this energetic separation could considerably decrease upon adsorption.

In the meantime a molecular orbital cluster study of molecular oxygen on $\mathrm{Ag}(110)$ was performed by Selmani et al. (44). Up to 16 silver atoms were used in their calculations. The surface layer was constructed from the known bulk atomic position of silver, i.e., no relaxation was allowed for. The $\mathrm{O}-\mathrm{O}$ distance was taken to be $0.15 \mathrm{~nm}$ as 2 derived from the vibrational data $(32,43)$. This $\mathrm{O}-\mathrm{O}$ distance was also used for the evaluation of surface extended X-ray absorption fine structure (SEXAFS) spectra from $\mathrm{O}_{2}-\mathrm{Ag}$ by Puschmann et al. (45), which then allowed the determination of the $\mathrm{Ag}-\mathrm{O}$ distance as $0.232 \mathrm{~nm}$. The four sites of $C_{2 \mathrm{v}}$ symmetry were scrutinized, which yielded a total of 12 conformations to be submitted to calculation. Comparison of the 12 calculated local density of states (LDPS) distributions with the UPS data from Prince and Bradshaw (41), Barteau and Madix (36), and Rao et al. (46) then left two "long bridge" (LB) possibilities denoted as $\mathrm{LB}(\|\mathrm{S},\| \mathrm{G})$ and $\mathrm{LB}(\| \mathrm{S}, \perp \mathrm{G})$, with a preference for the latter. According to $L B(\| S, \perp G)$ the oxygen molecule is coordinated to two opposing silver ridge atoms, thus bridging the groove.

According to $\mathrm{LB}(\|\mathrm{S},\| \mathrm{G})$, the oxygen molecule is in the groove, parallel to the direction of the groove, and is coordinated to four silver atoms, two in the 
groove and two in the ridges. The LB $(\| \mathrm{S}, \perp \mathrm{G})$ coordination led to an annotation which closely matched the one chosen by Prince and Bradshaw $(41)$, with the exception of the peak at $5.6 \mathrm{eV}$, which was proposed to contain some oxygen-derived $\pi_{\mathrm{u}}$ and $p \sigma_{\mathrm{g}}$ contributions along with the "umklapp" electrons. Although the LB $(\|\mathrm{S},\| \mathrm{G})$ coordination yielded a LDOS in reasonable agreement with the measurement UPS spectra, the character of the states in the valence region was more complex due to a prominent role of the contribution of silver states in the strong lines, i.e., the contribution of the oxygen orbitals was "smeared out" over a large number of peaks.

The preference for the $L B(\| S, \perp \mathrm{G})$ coordination was based on the work of Prince et al. (45), who found that the peak at $-1.1 \mathrm{eV}$ undergoes a slight shift when the polarization of the radiation is changed from $s$ to $p$. This is expected for the composite peak for $L B(\| S, \perp G)$ but not for $L B(\|S\| G$,$) . Further$ concomitant evidence stems from electron-stimulated desorption work of Madey et al. (47), which was also in favor of an oxygen molecule perpendicular to the groove. Therefore the coordination shown in Fig. 3 is the most likely one according to these authors (44).

Molecular oxygen adsorption has been studied to a lesser extent on $\operatorname{Ag}(111)$ than on $\operatorname{Ag}(110)$, and moreover there are conflicting results. Grant and Lambert $(48,49)$ claimed the existence of a stable dioxygen species, coexisting with atomic oxygen, on the basis of isotope-exchange experiments. This state of oxygen was characterized by a thermal desorption peak at $380 \mathrm{~K}(!)$, and was denoted as $\alpha$-state. Most remarkably, the $\alpha$-state population was dependent not only on the total oxygen dose but also on the dosing pressure. For a total dose of $5 \times 10^{6}$ langmuirs (L), a pressure larger than $10^{-2}$ torr was required in order to adsorb amounts of $\alpha$-oxygen detectable

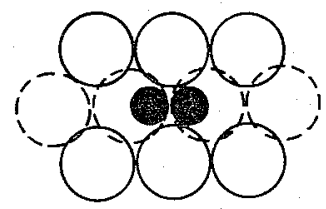

LBT6 //S //G

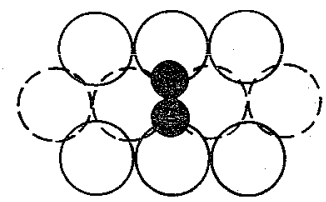

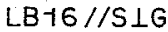

FIG. 3. Most likely structures for molecular oxygen on $\mathrm{Ag}(110)$ (44). 
in temperature-programmed desorption (TPD). Furthermore, this dioxygen species could not be prepared in isolation but was always accompanied by a much larger amount of desorbing atomic oxygen, characterized by a TPD peak at $580 \mathrm{~K}$. For a dose applied at 1 torr the population of the $\alpha$-state at saturation reached about $16 \%$ of the one of atomic oxygen, and remained stable at room temperature for many minutes. A Redhead analysis of the TPD peak of the $\alpha$-state yielded a desorption energy of $94 \pm 2 \mathrm{~kJ} / \mathrm{mol}$, close to the value determined in an Arrhenius plot, which yielded $90 \mathrm{~kJ} / \mathrm{mol}$. Furthermore, the $\alpha$-state was characterized by typical first-order kinetics.

Most interestingly, the amount of $\alpha$-state oxygen could be strongly increased (up to $60 \%$ of the $\beta$-state, which was not affected) by increasing the amount of subsurface oxygen in the sample as determined by TPD. Since no scrambling of ${ }^{16} \mathrm{O}_{2}$ and ${ }^{18} \mathrm{O}_{2}$ occurred at all, the authors concluded that they had detected for the first time a dioxygen species that was stable at room temperature and even above.

Another distinction between $\alpha$-and $\beta$-state oxygen could be made by means of photoelectron spectroscopy. The $\alpha$-state was characterized by an $\mathrm{O}(1 s)$ peak at $532.6 \mathrm{eV}$ and the $\beta$-state by one at $529.8 \mathrm{eV}$. Furthermore, the angular distributions of the $\mathrm{O}(1 \mathrm{~s})$ photoelectrons at $532.6 \mathrm{eV}$ (attributed to molecular oxygen) and the $\mathrm{O}(K L L)$ Auger electrons, taken to be representative of atomic oxygen after flash-off of the molecular state, were completely different. The photoelectron signal increased strongly with increasing emission angle (angle between surface normal and "viewing direction" of analyzer), whereas the Auger signal strongly decreased. This behavior was attributed to the fact that molecular oxygen was present upon, and atomic oxygen embedded in, the surface following the arguments proposed by Fraser et al. (50). The larger width of the $\mathrm{O}(1 \mathrm{~s})$ photoelectron peak at $532.6 \mathrm{eV}$ compared to the one at $529.8 \mathrm{eV}$ was attributed to a "head-on" configuration of molecular oxygen, thus causing heterogeneify between the two oxygen atoms. Ultraviolet photoelectron (UP) spectra showed that the dioxygen species introduced two states, 3.3 and $9.6 \mathrm{eV}$ below the Fermi edge, attributed to an antibonding and a bonding level formed from the $\mathrm{Ag}(4 d)$ and $\mathrm{O}_{2}\left(\pi_{\mathrm{g}}\right)$ levels.

For the pressure-dependent formation of their molecular oxygen Grant and Lambert (31) proposed a model in which single, isolated adsorption sites are needed for molecular adsorption, whereas neighboring twofold sites are filled with atomic oxygen. At $300 \mathrm{~K}$ the mobility of $\mathrm{O}_{\mathrm{ad}}$ was claimed to be sufficiently low for local ordering to a $4 \times 4$ adlayer, which would destroy the isolated single sites for dioxygen. Competition between ordering and speed of adsorption could then explain the observed pressure dependence.

Campbell (51) studied molecular oxygen on $\mathrm{Ag}(111)$ as well but could not reproduce the stable dioxygen species reported by Grant and Lambert (31). In fact his results for $\mathrm{Ag}(111)$ qualitatively resembled the results for $\mathrm{Ag}(110)$. 
At a sample temperature of $147 \mathrm{~K}$, low-pressure dosing of oxygen yielded a molecular type of oxygen as identified by its desorption temperature of $217 \mathrm{~K}$. This peak shifted only to a small extent with precoverage, indicative of a firstorder process with no coverage dependence of the heat of adsorption. Contrary to the case of $\mathrm{Ag}(110)$ there was only very little competition between desorption and dissociation of the molecular species, as evidenced by the very small high-temperature desorption peak ( $2 \%$ of the molecular peak). The sticking coefficient of molecular adsorption is much lower on $\mathrm{Ag}(111)$ than on $\operatorname{Ag}(110)$, since saturation with this species required a 200 -fold increase of the dose. The saturation coverage was estimated to be about 0.5 oxygen atom per silver surface atom, similar to the value of 0.6 as determined by Barteau and Madix for $\mathrm{Ag}(110)(36)$. This yielded an approximate sticking probability of $5 \times 10^{-6}$ at $147 \mathrm{~K}$ as compared to $7 \times 10^{-4}$ for $\mathrm{Ag}(110)$ at $130 \mathrm{~K}$. Besides a small peak at $190 \mathrm{~K}$, which was attributed to steps introduced by imperfections of the (111) face, no further desorption peaks were ever observed. Unlike Grant and Lambert (3l) Campbell (5l) was not able to produce their stable molecular oxygen peak desorbing at $380 \mathrm{~K}$ by using their (highpressure) conditions. Trials led to the appearance of large amounts of impurities in TPD in addition to the usual $580 \mathrm{~K}$ desorption peak of atomic oxygen. It should be mentioned, however, that the discrepancy with respect to the stable molecular oxygen species calls for more investigation, since impurities alone are insufficient to cancel the very clear evidence for a stable molecular species as provided by the isotope-exchange experiments of Grant and Lambert (31).

Campbell finally proposed a three-step route for the adsorption of oxygen on $\mathrm{Ag}(111)$, the first step being the physisorption of a molecular precursor with a heat of adsorption of only $3 \mathrm{kcal} / \mathrm{mol}$ as derived from its TPD peak at $50 \mathrm{~K}$ (52). From a compilation of kinetic data he could derive an approximate structure of this adsorption potential model for $\mathrm{Ag}(110)$ as well as for $\mathrm{Ag}(111)$, which is characterized by activation barriers between physisorbed and chemisorbed molecular oxygen of 3.2 and $1.5 \mathrm{kcal} / \mathrm{mol}$ for $\mathrm{Ag}(111)$ and $\operatorname{Ag}(110)$, respectively. According to his evaluation the transfer from chemisorbed molecular to atomic oxygen is not activated relative to gas-phase $\mathrm{O}_{2}$.

For polycrystalline silver, TPD experiments had already been performed in 1976 by Ekern and Czanderna (53). However, the temperatures they adopted were not sufficiently low to enable the detection of molecularly adsorbed oxygen. This also holds for the photoelectron spectroscopic work of Evans et al. (54) in 1974.

Eickmans et al. (55), however, reported in 1985 the physisorption and chemisorption of molecular oxygen on polycrystalline silver films by means of UPS and XPS. Their results are in good agreement with the single-crystal work cited above. 


\section{Atomic Oxygen on Silver}

The dissociative sticking coefficient for oxygen on silver is low. With a value of $5-30 \times 10^{-4}(30,38,56,57)$, it is largest on $\operatorname{Ag}(110)$ among the principal crystal faces. Therefore, and because of the appealing structural phenomena exhibited by oxygen, this surface has been studied in most detail.

Bradshaw, Engelhardt, and Menzel $(56,58,59)$ used a combination of Auger electron spectroscopy (AES), LEED, and work function measurements. They found that with increasing oxygen exposure at room temperature a series of $p(n \times 1)$ LEED structures developed, with $n$ decreasing from 7 to 2 , the $p(2 \times 1)$ structure corresponding to the saturation coverage of 0.5 . The authors proposed the $n \times 1$ structures to reflect ideal coverages of $1 / n$. Rovida and Pratesi $(60-62)$ studied the system by the same techniques in combination with TPD measurements, but used high-pressure oxygen dosing in the range from $10^{-3}$ to 1 torr. They could reproduce the $4 \times 1,3 \times 1$, and $2 \times 1$ superstructures only after applying high pressures of oxygen, whereas at low pressures only very weak reflections could be observed. The $2 \times 1$ structure could be prepared by using temperatures during exposure of up to $570 \mathrm{~K}$. On the other hand, the $3 \times 1$ and $4 \times 1$ structures could be destroyed by heating to temperatures in excess of $420 \mathrm{~K}$, indicative of a higher mobility of oxygen in those phases. Furthermore AES and TPD showed that the coverages of oxygen were not in the proper ratio as proposed by the ideal $4 \times 1,3 \times 1$, and $2 \times 1$ structures. Rovida et al: therefore assumed a coverage in excess of 0.5 for the $2 \times 1$ structure. The proposed model for the saturated layer has a coverage of unity, with oxygen-oxygen distances of 0.41 and $0.35 \mathrm{~nm}$ corresponding roughly to the value in silver oxide. As pointed out by Campbell and Paffett (30), a more natural explanation for the deviation between structure and surface stoichiometry would be island formation of $(n \times 1)$ superstructure oxygen with $n>2$. This explanation is substantiated by experimental evidence. First of all, Campbell identified a new higher saturation coverage by dosing oxygen at 50 torr to the sample kept at $485 \mathrm{~K}$, which exhibited a $c(6 \times 2)$ LEED pattern corresponding to a coverage of 0.67 . Second, on $\mathrm{Ag}(110)$ the desorption peak maximum of oxygen shifts to higher temperature with increasing coverage, which is indicative of a corresponding increase in heat of adsorption and hence represents a thermodynamic driving force for island formation. Therefore there is no evidence for a saturation coverage of unity and the new saturation value of 0.67 detected by Campbell must be regarded as the maximum achievable so far. As indicated by TPD, which shows a distinct new peak at $565 \mathrm{~K}$ together with the normal $p(2 \times 1)$ peak at $605 \mathrm{~K}$, the compression of the $p(2 \times 1)$ phase to the $c(6 \times 2)$ is accompanied by a stepwise decrease in differential heat of adsorption of about $7 \%$. This value was estimated by first-order Redhead analysis with a 
preexponential factor of $10^{15} \mathrm{~s}^{-1}$, which yielded activation energies for desorption of 42.4 and $39.5 \mathrm{kcal} / \mathrm{mol}$ for $p(2 \times 1)$ and $c(6 \times 2)$ oxygen, respectively.

The atomic nature of the new oxygen species was further substantiated by XPS. The composite $\mathrm{O}(1 s)$-photoelectron peak could be synthesized with the usual low-coverage peak at $528.1 \mathrm{eV}$ with an FWHM of $1.7 \mathrm{eV}$ and a slightly shifted contribution from the new oxygen species characterized by a maximum at $528.3 \mathrm{eV}$ and a slightly larger FWHM of $1.9 \mathrm{eV}$.

In an early attempt Heiland et al. (63) used low-energy helium ion scattering for the determination of the positions of the oxygen atoms causing the $p(n \times 1)$ LEED structures. They found a strong azimuthal anisotropy for the $\mathrm{He}^{+}$ions scattered from oxygen adatoms. The oxygen appeared to be much more "visible" to this very surface-sensitive technique when the plane of measurement was in the (110) direction (parallel to troughs) than when it was in the (100) direction (perpendicular to the channels). By calibrating their scattered helium ion intensities via AES and work function measurements and by using various theoretical scattering cross sections, they arrived at a model which was in agreement with experiment. According to the authors, oxygen in the $p(2 \times 1)$ structure is located in the troughs between two opposing ridge silver atoms and bridging two "second-plane" silver atoms in the bottom of the trough. The position of oxygen with respect to the "first-" and "second-layer" atoms was estimated as slightly below or in the plane of the ridge atoms. One of the approximate assumptions made for arriving at this conclusion was the absence of adsorbate-induced reconstruction of the $\mathrm{Ag}(110)$ surface. One argument in favor of this assumption was based on previous low energy ion scattering (LEIS) work on oxygen adsorbed to $\mathrm{Ni}(110)$, where reconstruction does occur, leading to a drastically different azimuthal dependence of oxygen and silver signais in the spectrum. The second argument cited was that the sequential appearance of $(n \times 1)$ structures with $n=7$ to 2 , with increasing exposure, would necessitate a continuous reordering of the silver surface atoms.

The $C_{2 \mathrm{v}}$ symmetry derived from the observation of a single energy-loss peak at $39 \mathrm{meV}$ for atomic oxygen on $\mathrm{Ag}(110)$ (32) is in accordance with the LEIS work above.

Prince and Bradshaw (4I) studied oxygen in the $3 \times 1$ structure by angularly resolved UPS. In normal emission three oxygen-induced peaks were found at 3.0,5.2, and $8.2 \mathrm{eV}$ below the Fermi level. Moving in an off-normal direction along the [001] azimuth gave rise to the appearance of another peak above the silver $d$-band, which showed dispersion in that its position varied between 1.5 and $2.5 \mathrm{eV}$. This feature was attributed to an oxygen $2 p_{y}$-derived adsorbate band, which is antibonding in character with respect to the oxygensilver band (the index $y$ stands for the [001] direction). On the basis of the 
theoretical work of Rösch and Meuzel (64) ( $X \alpha$ cluster calculations) and Martin and Hay (65) (ab initio) SCF CI calculations for 26 atom clusters of silver), the peak at $8.2 \mathrm{eV}$ was attributed to bonding levels with respect to the oxygen-silver bond containing bonding contribution of $2 p_{y}, 2 p_{x}$, and $2 p_{z}$. No unambiguous assignment was possible for the peak at $3.0 \mathrm{eV}$. As for the molecular oxygen described in the foregoing case, the peak at $5.2 \mathrm{eV}$ was attributed to "umklapp" electrons.

In contrast to the foregoing work, Bange et al. (66) proposed a model for atomic oxygen on $\operatorname{Ag}(110)$ in which the oxygen atom cannot be in a highly symmetric bridge or on-top site. This proposal is based on electron-stimulated desorption ion angular distribution (ESDIAD) measurements, which showed that the pertinent silver-oxygen band(s) must have an appreciable component in the [001] azimuthal direction. As a possible explanation they proposed an adsorption-induced reconstruction of the $\operatorname{Ag}(110)$ surface brought about by the strength of the silver-oxygen bond. This would cause the oxygen atoms in the troughs to "lean" toward one of the ridge silver atoms. It should be mentioned, however, that the authors themselves admit that they could not rule out definitely the possibility of ESDIAD sampling only a minor fraction of the oxygen atoms, the adsorption symmetry of which thus need not necessarily reflect that of the majority of the oxygen atoms.

Lin and Garrison (67) modeled the interaction of oxygen and $\mathrm{Ag}(111)$ by using London-Eyring-Polanyi-Sato (LEPS) potentials, which were made to reproduce as many available basic experimental features as possible. This semiempirical approach yielded a description according to which the longrange $(\sim 20 \AA)$ (repulsive) force between oxygen atoms in the troughs, forming the $(7 \times 1)$ structure, was caused by an ionic oxygen-oxygen antibonding potential with a net charge of -0.4 on the oxygen atoms. With a view to modeling the attractive (short-range) force perpendicular to the troughs (in the [001] direction), the oxygen-oxygen antibonding potential had to be made anisotropic. In this way the features of the oxygen- $\mathrm{Ag}(110)$ interaction known at that time (1984) could be reproduced:

Atomic oxygen on $\mathrm{Ag}(111)$ is difficult to prepare $(51,68)$ because of the very low dissociative sticking coefficient for oxygen adsorption, which necessitates a very low CO partial pressure for the suppression of "cleaning-off" reactions during dosing. Campbell (51) estimated the dissociative sticking coefficient for oxygen to be around $10^{-6}$ at $490 \mathrm{~K}$, in agreement with previously determined room-temperature values in the range $10^{-5}-10^{-6}(49,57,69)$. By hightemperature dosing in a microreactor (5-torr $\mathrm{O}_{2}$ ) and subsequent TPD in UHV he found a single desorption peak at $579 \mathrm{~K}$, slightly below the value of the low-temperature shoulder found for desorption of oxygen from his saturated $(\theta=0.67) \operatorname{Ag}(110)$ face characterized by the sharp $c(6 \times 2)$ LEED structure. The binding energy for atomic oxygen in XPS with a value of $528.2 \mathrm{eV}$ was very close to the value on $\mathrm{Ag}(110)$, as measured by the same 
author. The saturated oxygen overlayer gave rise to a sharp $p(4 \times 4)$ LEED pattern, as found, before by others $(57,70)$. On the basis of a comparison with $\mathrm{Ag}(110)$ as regards the AES oxygen/silver peak ratio, a coverage of $0.41( \pm 10 \%)$ was attributed to this structure provided it had been prepared by high-pressure dosing, whereas cleaning-off reactions precluded the preparation of coverages larger than a few percent by low-pressure exposure. The oxygen adatoms tended to coalesce into islands with local $p(4 \times 4)$ structure. This was indicated by the increase of the TPD peak maximum with increasing oxygen coverage (suggesting a net gain in heat of adsorption). Direct proof was obtained by the observation of the $p(4 \times 4)$ superstructure even at much smaller coverages provided it had been prepared at $490 \mathrm{~K}$.

The evaluation of the temperatures at the desorption peak maxima according to the Redhead approach with a preexponential factor of $10^{15} \mathrm{~s}^{-1}$ yielded an activation energy for the desorption of oxygen of $39.9 \mathrm{kcal} / \mathrm{mol}$, about $7 \%$ lower than the value determined for $\operatorname{Ag}(110)$ with the same preexponential term.

Grant and Lambert (49) found that an $\mathrm{Ag}(111)$ surface "roughened" by $500-\mathrm{eV}$ argon bombardment did not exhibit a detectable increase in the dissociative sticking coefficient of oxygen. This is in line with the observation of Campbell that the bottleneck to oxygen adsorption is sticking in the chemisorbed molecular oxygen state (roughly $10^{-6}$ ), rather than the transition from molecular to atomic oxygen. The authors applied the model proposed by Bowker (71) in order to determine the pairwise interaction energy of oxygen atoms in the islands from their thermal desorption data and found a value of $20 \mathrm{~kJ} / \mathrm{mol}$.

The adsorption studies at $300 \mathrm{~K}$ could be modeled by Langmuir kinetics showing that random adsorption occurs over the full coverage range, with atomic oxygen being immobile on the time scale of the adsorption experiments at room temperature.

An early extensive investigation of the oxygen $\mathrm{Ag}(111)$ system by Rovida et al. $(70)$ is in agreement with these observations. According to these authors, ordering of oxygen into the $(4 \times 4)$ superstructure did not occur below $400 \mathrm{~K}$. They also pointed out that the (111) plane of $\mathrm{Ag}_{2} \mathrm{O}$ matches the $\operatorname{Ag}(111)$ face to within $0.5 \%$. With its mesh size of $0.473 \mathrm{~nm}$, a single slab of this oxide could explain the observed $(4 \times 4)$ superstructure as well. Grant and Lambert (49) accepted this proposal on the basis of evidence from their XPS results. The photoelectron peak they attributed to adsorbed atomic oxygen at $529.8 \mathrm{eV}$ decreased monotonically with increasing off-normal detection, which is characteristic of a species embedded in, rather than adsorbed on top of, a surface (50). The discrepancy between the binding energies of atomic oxygen as found by Campbell $(528.3 \mathrm{eV})$ and Grant $(529.8 \mathrm{eV})$ has not been convincingly explained as yet. 


\section{Subsurface Oxygen in Silver}

Most of the authors cited in this section reported on another oxygen species encountered upon high-temperature treatment of silver in the presence of oxygen. This species is referred to as subsurface oxygen. By its very nature a detailed characterization by surface science techniques is difficult. An initial systematic single-crystal study of subsurface oxygen was performed by Rovida et al. for $\operatorname{Ag}(111)(70)$. These authors found that exposure of their crystal to oxygen at temperatures in excess of $470 \mathrm{~K}$ resulted in a second very wide, hightemperature desorption peak centered at $780 \mathrm{~K}$. Exposures above $525 \mathrm{~K}$ resulted in the disappearance of the normal associative oxygen desorption peak, whereas the subsurface oxygen remained. By systematically varying the temperature and oxygen pressure during dosing the authors were able to construct the "stability diagram" of the total amount of oxygen chemisorbed and absorbed, as shown in Fig. 4. A comparison with the phase diagram of $\mathrm{Ag}_{2} \mathrm{O}$, shown in the figure as well, shows that subsurface oxygen is more stable than bulk silver oxide since the range of temperatures and pressures studied

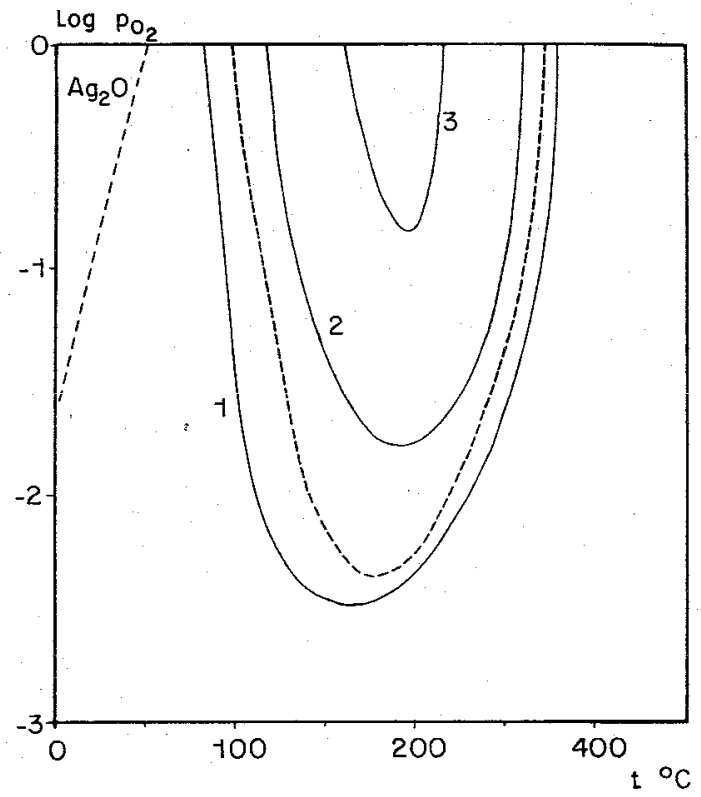

Fig. 4. Stability diagram for quantity of oxygen ad/absorbed on $\mathbf{A g}(111)$ as a function of pressure (torr) and temperature at exposure. The dashed line between curves 1 and 2 corresponds to the limits between which the $(4 \times, 4)$ superstructure is observed. The dashed line in the upper left-hand corner is the equilibrium curve for the decomposition of $\mathrm{Ag}_{2} \mathrm{O}$. Lines 1,2 , and 3 correspond to $0.3,0.6$, and 0.9 of the maximum amount (70). 
extended beyond the stability limits of the latter, Under no circumstances did the high-temperature oxygen species give rise to any specific LEED pattern. The subsurface oxygen found by the same authors (60) in $\mathrm{Ag}(110)$ displayed features not different from the one in $\operatorname{Ag}(111)$.

Backx et al. (32) studied subsurface oxygen in $\mathrm{Ag}(110)$ with oxygen-isotope techniques. In line with the findings of Rovida et al. for $\mathrm{Ag}(111)$ they found that subsurface oxygen does not involve mere dissolution of oxygen in the bulk, since this state could be saturated completely upon moderate exposure. This finding was based on their TPD work. Exposing a freshly sputtercleaned surface (free of subsurface oxygen) to a $800 \mathrm{~L}$ oxygen dose at room temperature resulted in the usual $585 \mathrm{~K}$ oxygen desorption peak. A consecutive identical exposure and desorption experiment, however, yielded a $70 \%$ larger desorption peak. After six further identical cycles the amount of desorbing oxygen did not change anymore, nor did heating the crystal to $725 \mathrm{~K}$ for $10 \mathrm{~min}$. From all these findings they concluded that in the first few cycles oxygen was lost to the subsurface state, whereas the stable saturation (in contrast to mere dissolution in the bulk) was proven by the heat treatment at $725 \mathrm{~K}$.

Saturation of the subsurface state with ${ }^{16} \mathrm{O}$ prior to adsorption of ${ }^{18} \mathrm{O}_{2}$ at room temperature followed by thermal desorption revealed that subsurface ${ }^{16} \mathrm{O}$ interchanged with adsorbed ${ }^{18} \mathrm{O}$, as demonstrated by substantial peaks of ${ }^{16} \mathrm{O}_{2}$ and ${ }^{16} \mathrm{O}^{18} \mathrm{O}$ appearing close to the "normal" $585 \mathrm{~K}$ peak. Interestingly, the ${ }^{16} \mathrm{O}_{2}$ and ${ }^{16} \mathrm{O}^{18} \mathrm{O}$ peaks were shifted to slightly higher temperatures (12 and $6 \mathrm{~K}$, respectively), indicative of the fact that the interchange takes place close to the desorption temperature and therefore has to be accounted for in a kinetic scheme for this process.

Campbell and Paffett (30) identified subsurface oxygen by its reappearance at the surface above $460 \mathrm{~K}$ after titration of adsorbed oxygen in the $c(6 \times 2)$ structure on $\mathrm{Ag}(110)$ with $\mathrm{CO}$ at room temperature. This appearance of subsurface oxygen could be monitored by cleaning it off the surface with $\mathrm{CO}$ and monitoring the $\mathrm{CO}_{2}$ production as a function of sample temperature. This yielded a broad peak extending from 460 to $630 \mathrm{~K}$. After titration at room temperature the subsurface (unreactive) oxygen produced an XPS peak at $528.4-528.6 \mathrm{eV}$ with an FWHM of $2.0 \mathrm{eV}$.

\section{B. Modification of Oxygen Species by Coadsorbed Alkaline Metals}

A number of articles report about the characterization of alkaline metals on various single-crystal silver faces and the coadsorption of oxygen. For example, sodium has been studied on $\operatorname{Ag}(110)(72,73)$ and $\operatorname{Ag}(100)(74)$, potassium on $\operatorname{Ag}(100)$ (75), rubidium on $\operatorname{Ag}(111)$ (76), cesium on $\operatorname{Ag}(111)$ 
$(77,78)$, and even lithium on $\operatorname{Ag}(111)(79)$. Because the aim of this section is to focus on the speciation of oxygen, the coadsorbate systems will not be discussed in full. Rather, a summary will be given of the changes in oxygen species by the coadsorption of alkali metals.

Parker and Rhead (79) studied the oxidation of lithium monolayers on $\mathrm{Ag}(111)$ by $\mathrm{AES}$, work function measurements, and secondary electron emission. They found that oxygen adsorption stabilizes lithium on the surface, thus preventing it from dissolution into the bulk. The stoichiometry of the saturated $\mathrm{Li} / \mathrm{O}$ coadsorbate was constant up to the first lithium monolayer. During the oxidation of a lithium-precovered surface the authors found interesting changes in work function until saturation was achieved. After a first steep decrease proportional to $\theta_{\mathbf{L}:}^{4}$, the work function increased again until a saturation value larger than the one prior to oxygen exposure was reached. The authors proposed a model according to which oxygen initially is trapped in a mobile molecular precursor state from which it dissociates into atoms, which at low $\mathrm{O} / \mathrm{Li}$ ratio are "capped" by a cluster of four lithium atoms. With increasing exposure to oxygen the adsorbate then turns gradually to a "lithium oxide" structure.

Briggs et al. (72) studied coadsorption of oxygen and sodium on $\mathrm{Ag}(110)$ by XPS and UPS. As for lithium the saturation stoichiometry of the coadsorbate layer was found to be independent of sodium coverage. This stoichiometry was proposed as $\mathrm{Na}_{2} \mathrm{O}$ by using sodium formate as a reference compound for XPS. Sodium precoverages in excess of a monolayer produced a new oxygen peak in XPS with higher binding energy, which was attributed to oxygen anions between two sodium layers, rather than in a "surface compound," as found at low coverages. The oxygen-derived peak in UPS about $3 \mathrm{eV}$ below the Fermi level did not change much in the presence of sodium. Therefore the authors concluded that the valence electronic structure of oxygen is not altered drastically by sodium coadsorption.

Garfunkel et al.(74) investigated the coadsorption of oxygen and sodium on $\operatorname{Ag}(100)$ and found indications for at least two different oxygen species in this system. One of these was attributed to the molecular state based on the appearance of a peak at $77 \mathrm{meV}$ in HREELS, together with a broad peak around $30-40 \mathrm{meV}$ characteristic of atomic oxygen. The molecular state could be populated at room temperature only at exposures sufficient for reaching the nearly saturated layer. Furthermore, at temperatures above $300 \mathrm{~K}$ this state disappeared, substantiating its weakly bound nature.

Kitson and Lambert (75) identified three oxygen species on potassiumpredosed $\operatorname{Ag}(100)$ attributed to atomic oxygen, molecular oxygen, and "dissolved" oxygen. Contrary to the case of sodium described above, the appearance of the molecular oxygen species was shown to be associated with subsurface potassium. Evidence for the molecular state was derived from 
isotope mixing and $\mathrm{CO}$ titration experiments as well as from its low activation energy for desorption of about $90 \mathrm{~kJ} / \mathrm{mol}$.

The atomic state of oxygen was found to be unstable in the presence of potassium, because AES was not able to detect it in initial experiments. Obviously potassium caused oxygen to populate the subsurface state. After repeated cycles of adsorption/desorption the subsurface state was saturated well enough to produce atomic oxygen on the surface. Potassium dissolved easily as well and its removal required heating to temperatures above $870 \mathrm{~K}$. Thermal desorption only produced $\mathrm{O}_{2}^{+}$and $\mathrm{K}^{+}$and never clusters consisting of combinations of $\mathrm{O}, \mathrm{K}$, and $\mathrm{Ag}$. The $\ln p$ versus $1 / T$ analysis of the associative desorption peak for atomic oxygen yielded an activation energy of $170 \pm 20 \mathrm{~kJ} / \mathrm{mol}$, close to the value for a clean $\mathrm{Ag}$ surface, which was attributed to a concomitant loss of potassium to the dissolved state during desorption of the oxygen that previously stabilized it at the surface. A fourth oxygen species only appeared at large potassium precoverages and was therefore attributed to the formation of $\mathrm{KO}_{2}$. Further evidence was derived from LEED, because the superstructure of this phase could be interpreted in terms of a distorted [001] layer of $\mathrm{KO}_{2}$.

The influence of coadsorbed rubidium on oxygen speciation on $\mathrm{Ag}(111)$ was studied by Goddard and Lambert (76). The results from this study closely match those found for potassium described above, albeit that the molecular state of oxygen was bound more tightly $(\sim 100 \mathrm{~kJ} / \mathrm{mol})$. The saturation composition of submonolayer doses of $\mathrm{Rb}\left(\theta_{\mathrm{Rb}} \leq 0.5\right)$ reached after oxygen exposure was estimated to be in the range $\mathrm{RbO}_{0.33-1.0}$.

Cesium finally shows a somewhat different behavior compared to potassium and rubidium. Grant and Lambert (78) found for the $\mathrm{Ag}(111)$ surface that cesium does not significantly penetrate the silver lattice by combining TPD and AES. At cesium precoverages below 0.05 , oxygen coadsorption to saturation yields TPD spectra very similar to those from clean $\mathrm{Ag}(111)$; above this value a complex TPD spectrum is observed until five distinct processes can be discerned at $\theta_{\mathrm{Cs}}>0.26$, in line again with the behavior of $\mathrm{Rb}$ described above. Despite the absence of evidence for subsurface cesium, a very weak peak at $380 \mathrm{~K}$ in the TPD spectrum, found for low cesium precoverages, is attributed to molecular oxygen. Since the same authors also found this state for clean $\mathrm{Ag}(111)$, as described above $(48,49)$, they did not associate it with cesium. Furthermore the associative oxygen desorption peak, just as the one for $\mathrm{K}$ and $\mathrm{Rb}$, does not shift in temperature in the presence of coadsorbed cesium, which is indicative of the fact that cesium does not influence the activation energy for desorption of oxygen found for clean $\operatorname{Ag}(111)$. The stoichiometry of an oxygen-saturated high-coverage cesium layer was estimated to be roughly $\mathrm{Cs}_{4.4} \mathrm{O}$. From these layers cesium only started desorbing after virtually all oxygen had been removed. Grant and Lambert 
proposed the formation of a Cs/Ag "surface alloy" as an explanation for this finding.

Campbell (77) studied Cs on $\mathrm{Ag}(111)$ as well. He determined the saturation coverage as being $\theta_{\mathrm{Cs}}=0.25$, involving a close-packed cesium layer with $2 \times 2$ structure. The behavior of cesium adlayers under ethylene epoxide synthesis conditions strongly deviated from the results for mere oxygen coadsorption as found by Grant and Lambert (78). First of all he found that the stoichiometry of the coadsorbate layer made under synthesis conditions could be expressed as $\mathrm{CsO}_{3}$, a phase which was present in islands giving rise to $(2 \sqrt{3} \times 2 \sqrt{3}) R 30^{\circ}$ LEED structure. This coadsorbate had a high thermal stability, as it desorbed above $610 \mathrm{~K}$, yielding $\mathrm{O}_{2}$ and Cs. Second, he found that some cesium did penetrate the bulk, as evidenced by a fraction of cesium desorbing above $700 \mathrm{~K}$.

As regards the state of the oxygen in the "postreaction" $\mathrm{CsO}_{3}$ phase, Campbell found that the shape of the $\mathrm{O}(K V V)$ AES signal was significantly different from the one measured for dissociatively adsorbed oxygen on clean $\mathrm{Ag}(111)$. Moreover, a quantitative comparison of the $\mathrm{AES} \mathrm{O} / \mathrm{Ag}$ signal ratio with the $p(4 \times 4)$ oxygen overlayer yielded an oxygen coverage between $\theta_{0}=0.70$ and 0.78 , depending on cesium precoverage. After these findings under reaction conditions Campbell succeeded in preparing the $(2 \sqrt{3} \times$ $2 \sqrt{3}) R 30^{\circ}$ LEED pattern by mere oxygen adsorption as well. AES showed that also the stoichiometry of this layer was slightly below " $\mathrm{CsO}_{3}$."

Since the TPD of oxygen did not much differ from the one of clean $\mathrm{Ag}(111)$, Campbell proposed that, although cesium and oxygen stabilized each other on the surface, the dominant interaction in " $\mathrm{CsO}_{3}$ " would be the bonding of oxygen atoms to silver.

The complex features of alkali metal/oxygen coadsorption certainly require further detailed investigations, which will hopefully shed even more light on the promoting action of alkali in catalytic ethylene epoxidation.

\section{Reactivity of the Silver Surface}

\section{A. The Epoxidation Reaction}

Klugherz and Harriott (17) published a detailed study on the kinetics of ethylene epoxidation catalyzed by an $8.1 \%$ (by weight) silver catalyst dispersed on a low-surface-area $\alpha$-alumina in the absence of a chlorine moderator in the feed or purposely added alkali promotor. The effects of changes in partial pressure of oxygen and ethylene were studied over a wide range at a total reactor pressure of $1.32 \mathrm{~atm}$ and $220^{\circ} \mathrm{C}$. As demonstrated in Figs. 5 and 6, at 


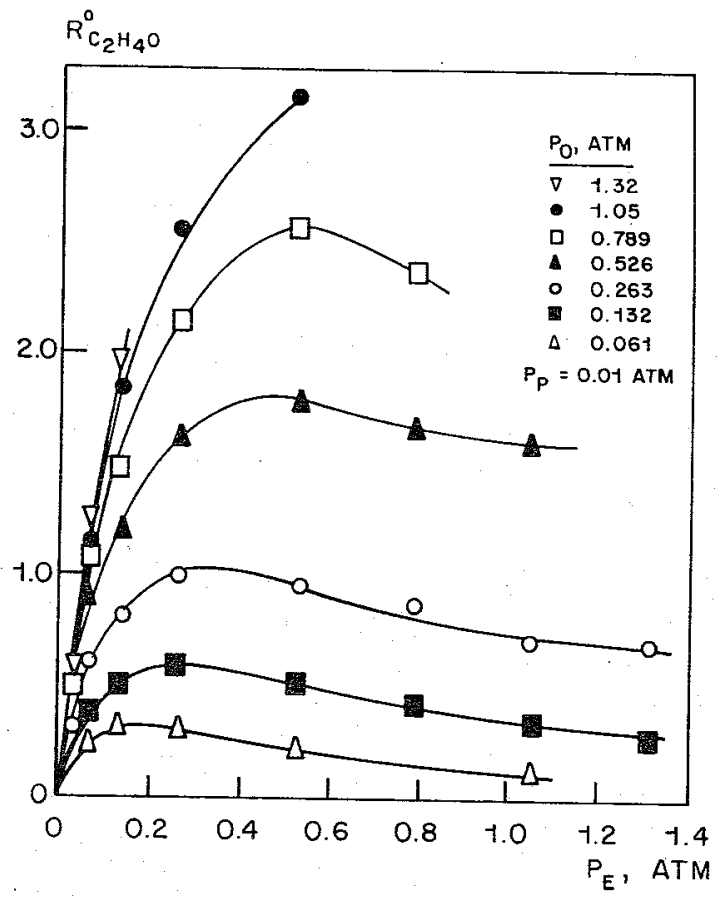

FIG. 5. Effect of ethylene pressure on the relative rate of ethylene oxide formation at $220^{\circ} \mathrm{C}(17)$. Reproduced by permission of the American Institute of Chemical Engineers.

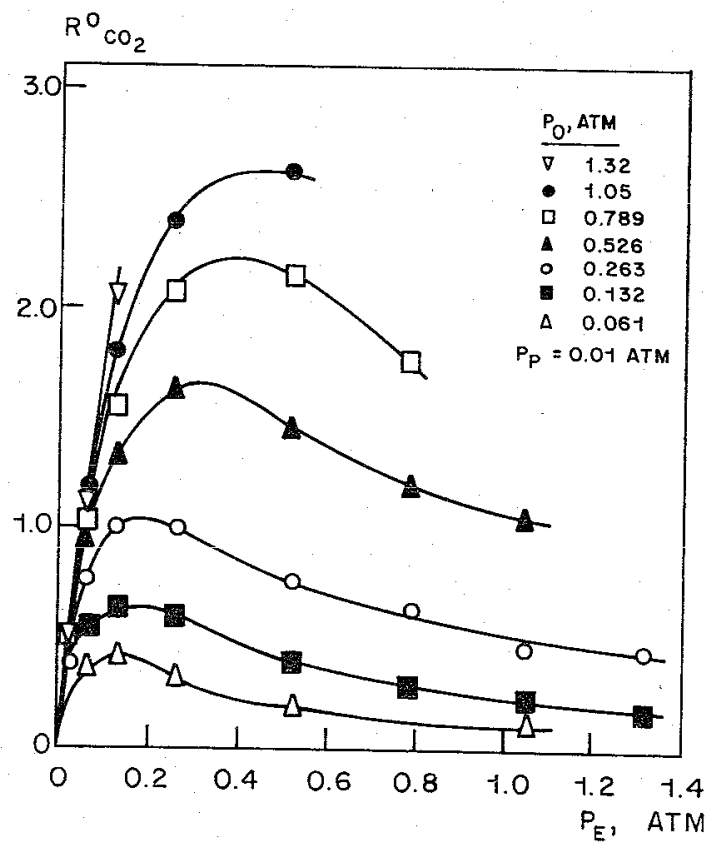

FIG. 6. Effect of ethylene pressure on the relative rate of carbon dioxide formation at $220^{\circ} \mathrm{C}(17)$. Reproduced by permission of the American Institute of Chemical Engineers. 
constant partial pressure of $\mathrm{O}_{2}$ the rates of ethylene epoxidation and total oxidation show a maximum with increasing partial pressure of ethylene. Figure 7 shows that at constant ethylene partial pressure the rate of ethylene epoxidation increases monotonically with the partial pressure of oxygen until an order in oxygen slightly higher than unity is reached. The maxima in the ethylene dependence of the reaction rate can be associated with a dual-site Langmuir-Hinshelwood mechanism for bimolecular reactions. In this mechanism, reaction occurs between two adsorbed species competing for sites on the surface of the catalyst.

Earlier kinetic data by Orzechowski and MacCormack $(4,80)$ and Nault et al. (15) can also be fitted to a rate expression developed on the basis of reaction between competitively adsorbed ethylene and oxygen molecules. The higher than first-order dependence on oxygen can only be understood if reaction takes place between adsorbed ethylene and adsorbed oxygen on top of an oxygen-covered silver surface. This is consistent with the fact that oxygen is adsorbed to silver under reaction conditions (5) and ethylene is adsorbed on silver covered with preadsorbed oxygen (28).

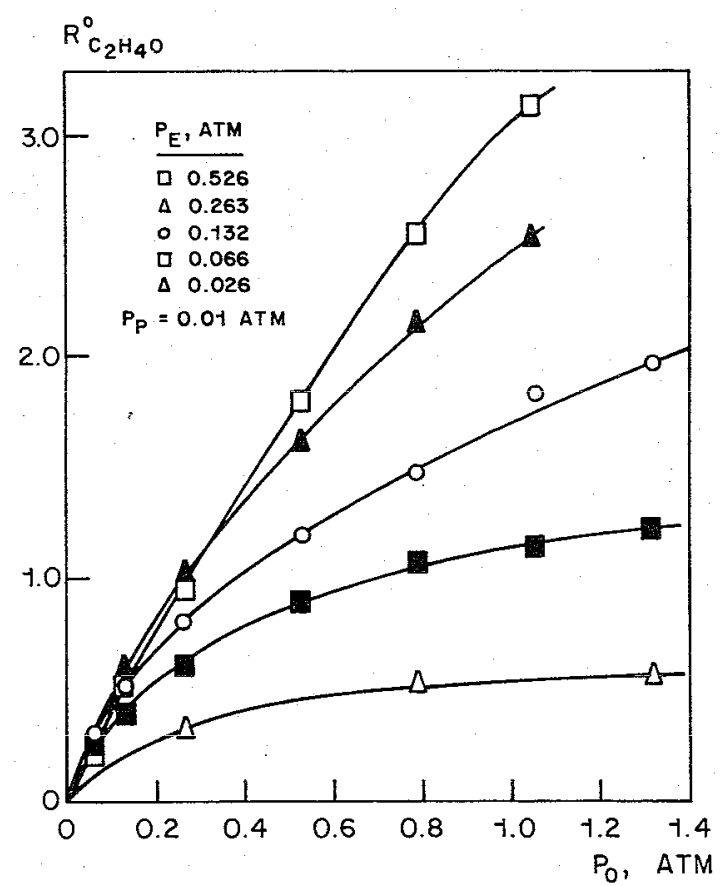

FIG. 7. Effect of oxygen pressure on the relative rate of ethylene oxide formation of $220^{\circ} \mathrm{C}(17)$. Reproduced by permission of the American Institute of Chemical Engineers. 
In a later study Kagawa et al. $(81,82)$ studied the yield of adsorbed ethylene and products of ethylene from silver covered with varying amounts of adsorbed oxygen. Generation of ethylene oxide and $\mathrm{CO}_{2}$ showed a bellshaped dependence on the concentration of preadsorbed oxygen, as can be seen from Fig. 8. Note that the maximum for ethylene oxide falls at higher oxygen surface concentration than does the maximum for carbon dioxide formation. The maximum amount of ethylene adsorbed as a function of oxygen coverage is in accordance with the results of Harriott et al. $(17,27 a)$, in that the rates of ethylene oxide and carbon dioxide formation showed maxima in their dependence on the partial pressure of oxygen.

Voge (14) has found that the rate of oxygen consumption upon reaction with ethylene differs by a factor of 200 from the rate of oxygen adsorption with oxygen coverage $\theta \simeq 0$.7. Belousov and Rubanik (16), using competitive

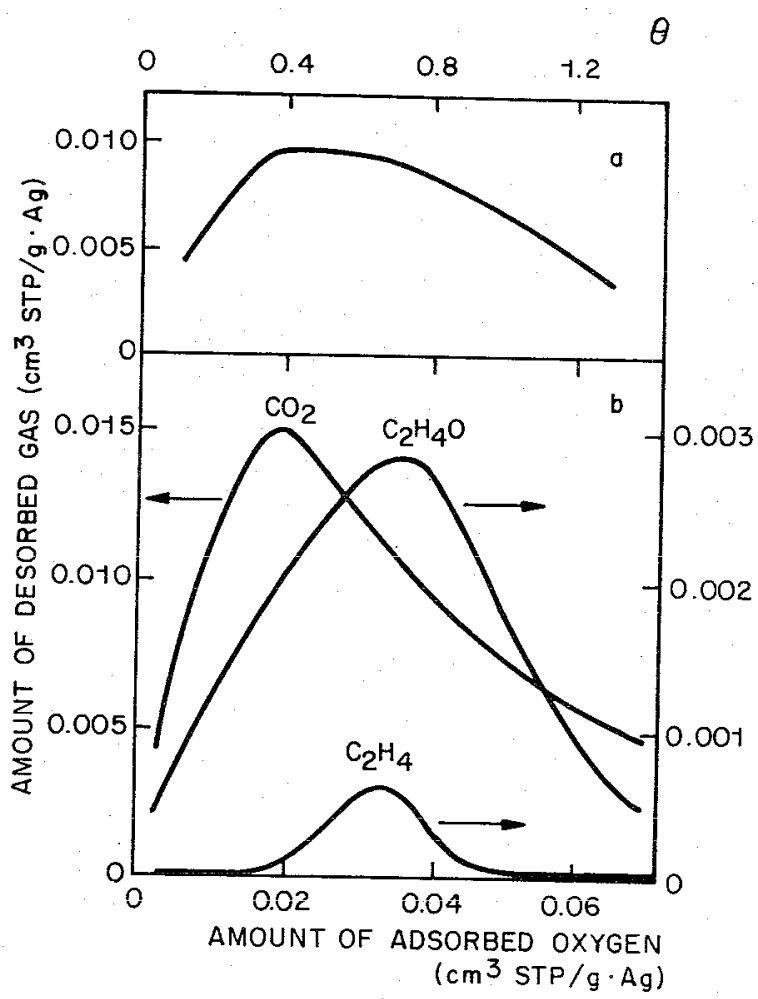

Fig. 8. Yield of desorbed gases following ethylene adsorption at $298 \mathrm{~K}$ and 300 torr for $30 \mathrm{~min}$ on $\mathrm{Ag}$ oxygen preadsorbed at $453 \mathrm{~K}$ : (a) the total amount of irreversibly adsorbed ethylene, which was calculated from the amounts of the respective components plotted in (b); $\theta$ is a measure of surface coverage equal to atoms of adsorbed $\mathrm{O} /$ surface silver atom (82). 
ethylene-propylene oxidation, as well as Kripylo et al. (14a) and Kenson and Lapkin (6) also conclude that reaction of ethylene with adsorbed oxygen is the rate-limiting step in the reaction toward epoxide. The result observed by Imre $(18)$, that the rate of ethylene epoxidation is significantly higher than the rate of oxygen dissociation at the surface, is consistent with a model according to which oxygen chemisorption is governed by the availability of bare surface sites created by ethylene oxide production. Kobayashi (16a), using transient response techniques, noted at $91^{\circ} \mathrm{C}$ a rapid reaction of ethylene to yield epoxide, but a slow desorption of $\mathrm{CO}_{2}$.

Thermodynamics teaches $(17,83,84)$ that the silver oxide phase cannot exist at the conditions normally used for ethylene epoxidation studies. The positive order of reaction rate with oxygen partial pressure suggests a low surface coverage with oxygen. Twigg (5) cites a surface coverage with oxygen between 0.2 and 0.3 . Similar results have been found for single-crystal "silver faces." Campbell and Paffett $(85,86)$ measured the amount of oxygen desorbing from silver single crystals after exposure to the epoxidation reaction. They found oxygen coverages of 34 and $4 \%$ for the (110) and the (111) face, respectively. Comparable results are reported by Tan et al. (87) for the $\operatorname{Ag}(111)$ face.

Several studies have been done to investigate the epoxide yield as a function of oxygen coverage $(11,12,25,82,88,89 c, d)$, by studying the stoichiometric reaction of ethylene with a silver surface precovered with oxygen. It is found that the epoxidation yield increased with increasing coverage of the silver surface by oxygen. Representative results from the work by Akella and Lee (88) are shown in Fig. 9. The selectivity measurements have been done in the absence of chlorine. Noteworthy is the high oxygen coverage required in order to have a high selectivity. Backx et al. (89) have shown on silver powders that only if the total amount of oxygen atoms adsorbed exceeds half of the number of silver surface atoms, will the adsorbed oxygen be in a state able to react with ethylene to yield the epoxide. Grant and Lambert (90) found that a pretreatment of their (111) single-crystal silver face in an ethylene-oxygen mixture is required in order to prepare a surface in a state which can produce epoxide from oxygen atoms. These two experiments were the first to indicate that the presence of subsurface oxygen is a necessity for adsorbed oxygen to react to epoxide.

Backx et al. inferred from the amount of epoxide formed that atomic oxygen had to give epoxide; Grant and Lambert showed that molecular oxygen also present on their surface did not react with ethylene to give epoxide. Herzog (19) reported that replacement of $\mathrm{O}_{2}$ by $\mathrm{N}_{2} \mathrm{O}$ in the reaction feed causes a significant drop in selectivity as well as activity. This is consistent with these observations, since in this way the surface oxygen coverage decreases significantly because of the slow rate of $\mathrm{N}_{2} \mathrm{O}$ decomposition (91). Stoukides 

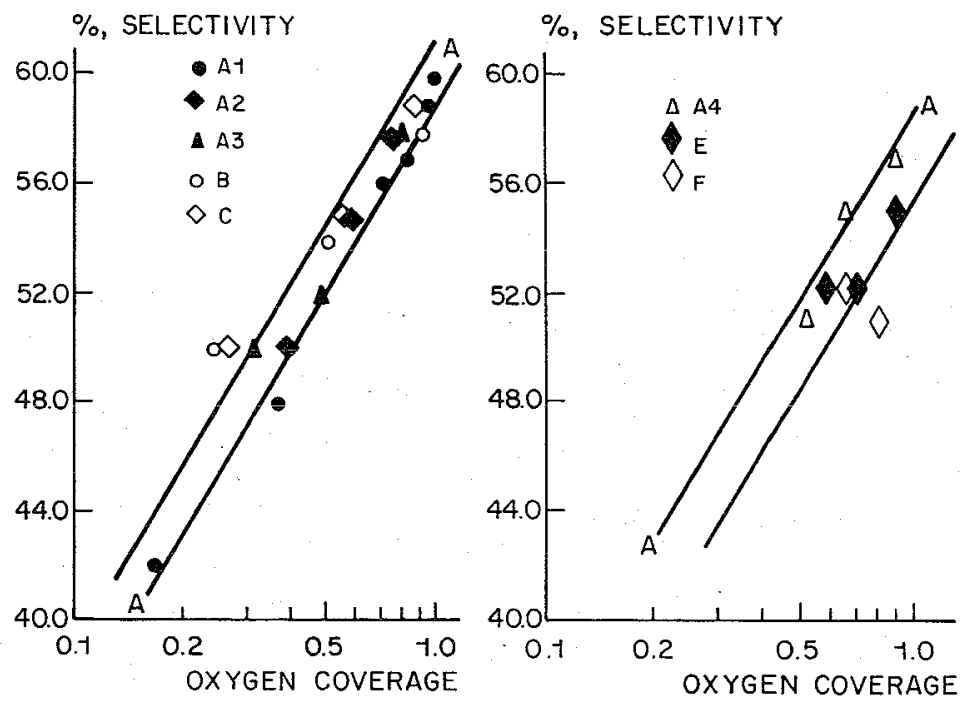

Fig. 9. Selectivity versus oxygen coverage for various catalysts (88).

and Vayenas (92) studied the epoxidation of ethylene by electrocatalytic generation of chemisorbed oxygen. They had to use a high temperature $\left(\sim 400^{\circ} \mathrm{C}\right)$ in order to have a finite oxygen conductivity. However, at this temperature the rate of oxygen desorption is significant. They found an increase in epoxidation selectivity with increasing voltage applied. Clearly, the surface oxygen concentration is enhanced in this way, which will increase the selectivity.

The selectivity turns out to depend not only on the oxygen coverage: replacing $\mathrm{C}_{2} \mathrm{H}_{4}$ by $\mathrm{C}_{2} \mathrm{D}_{4}$ in the feed $(93,94)$ gives a significant enhancement of the selectivity. For single crystals (94) as well as silver powder (93) the ratio $k_{1} / k_{2}$ has been found to increase by a factor of 5 . The rate of epoxidation has been found to increase, but the rate of the total oxidation reaction decreased. As shown in Fig. 10 for silver powder, chlorine adsorption (93) strongly suppresses the isotope effect.

Thus details of the reaction path of the oxygen-ethylene reaction itself influence the initial selectivity. This agrees with earlier suggestions by Krause (95) and Orzechowski and MacCormack (80), who proposed vinyl alcohol as an intermediate to total combustion of ethylene. There appears to be competition between the rate of oxygen insertion into the double bond and $\mathrm{C}-\mathrm{H}$ rupture leading to total combustion.

The selectivity of ethylene epoxidation at low conversion, governed solely by $k_{1} / k_{2}$, of spectroscopically pure silver powder (93) or single-crystal faces, is between 30 and $40 \%(86)$. Data by Campbell $(86)$ for single-crystal faces are 


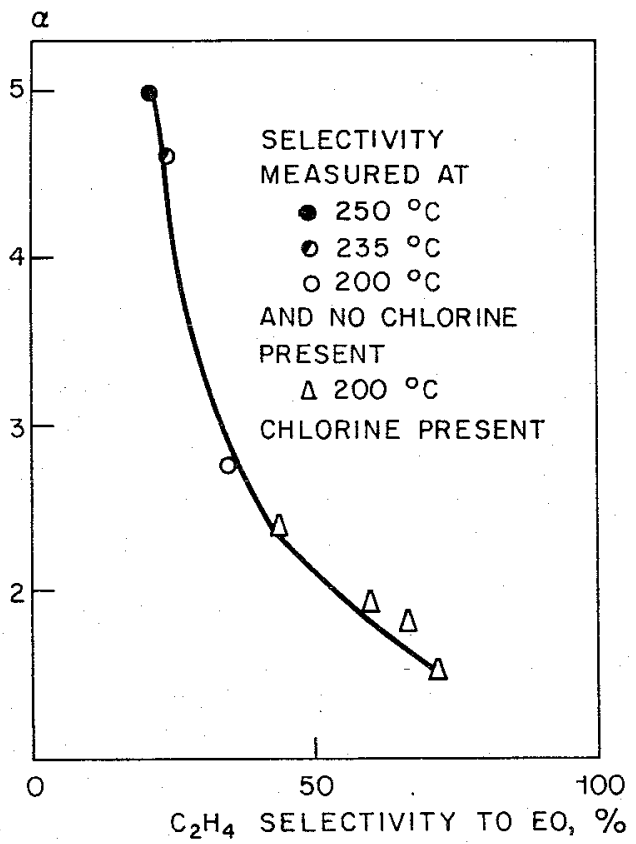

FIG. 10. Isotope effect as a function of selectivity.

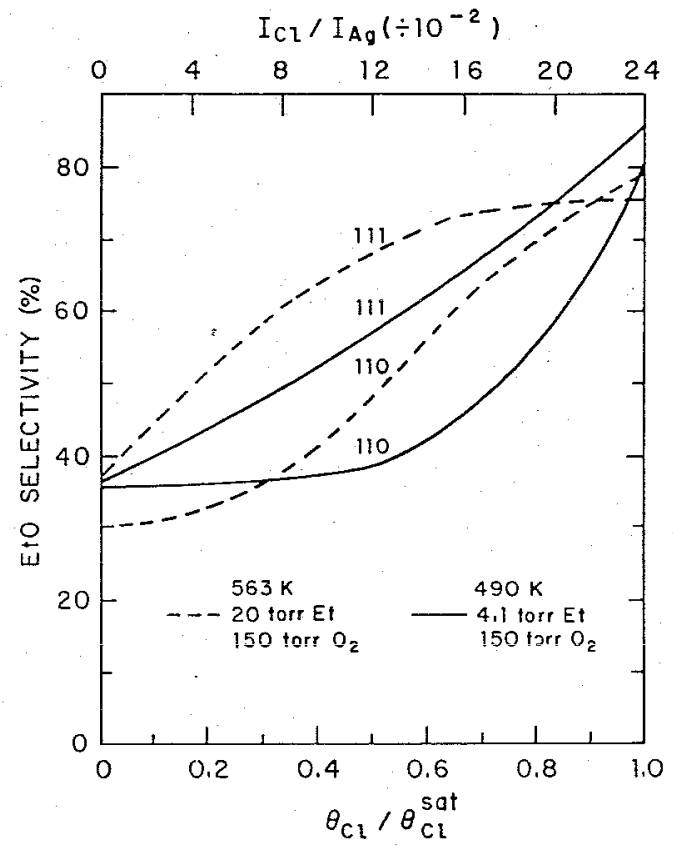

FIG. 11. Comparison of selectivity data for $\mathrm{Ag}(111)$ and $\mathrm{Ag}(110)$ faces as a function of chlorine coverage (86). 
shown in Fig. 11, which also indicates the dependence on the chlorine coverage. Chlorine adsorption has a significant effect on the selectivity; maximum values between 70 and $90 \%$ are found. There is a small dependence on temperature and gas-phase composition. Also, details in chlorine dependence differ for the two silver surfaces studied. Figure $12(85)$ shows a strong decrease in total conversion when the $\mathrm{Ag}(110)$ surface becomes covered with chlorine.

As follows from the work by Klugherz and Harriott (17), orders in ethylene and oxygen partial pressures may significantly depend on reaction conditions. As a result the reported activation energies also show a large scatter. A compilation can be found in a recent review by Sachtler et al. (12) or in the work by Grant and Lambert (94). On an Ag(111) face Grant and Lambert (94) find activation energies of 50 and $45 \mathrm{~kJ} / \mathrm{mol}$ for the epoxidation rate and total oxidation rate, respectively. Campbell and Paffett (29) report an

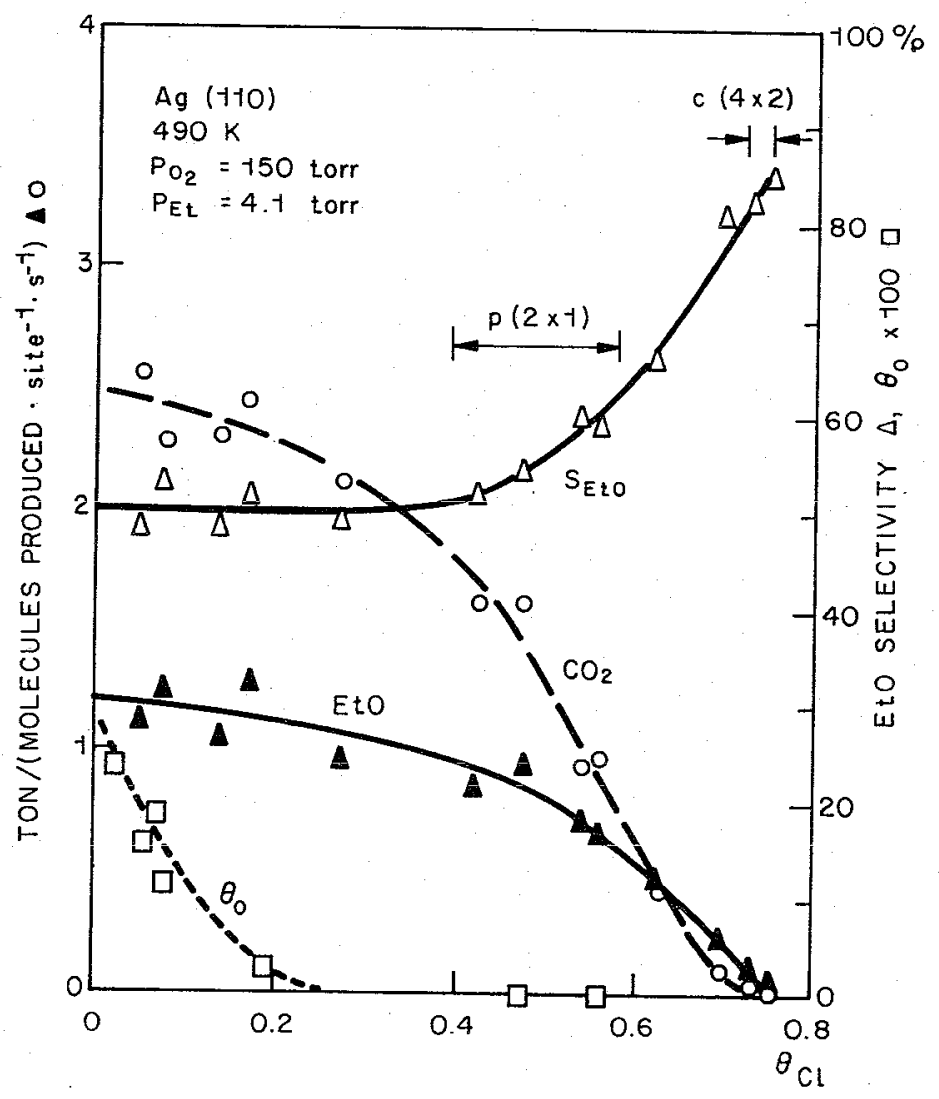

FIG. 12. Oxygen coverage and conversion rates as a function of chlorine precoverage (85). 
activation energy of $62 \mathrm{~kJ} / \mathrm{mol}$ for both reactions. These data are close to most data reported for practical catalysts.

Several explanations for the large effect of chlorine coverage have been proposed, which we will discuss in the next paragraph. All explanations agree in that chlorine adsorption apparently increases the concentration of that adsorbed surface oxygen species which also exists at high oxygen surface concentration and has a high selectivity for epoxidation upon reaction with ethylene. This concentration, as we have learned, is not easily reached under steady-state catalytic conditions.

Park et al. (25) as well as Bryce-Smith et al. (1c) report conditions where catalysts have a selectivity higher than the magic $86 \%$ selectivity barrier predicted by the adsorbed molecular oxygen epoxidation mechanism. In the absence of chlorine $(27 a, 96,97), \mathrm{CO}_{2}$ has been reported also to enhance the selectivity.

Most of the alkalis $(1 c, 26,98)$ and earth alkali metals $(7,99)$ have been reported to enhance the selectivity of the epoxidation reaction in a limited concentration regime and in the presence $(7,100)$ or absence of chlorine $(99)$. Spath et al. $(101,101 a)$ report a decrease in selectivity but an increase in activity using an $\mathrm{Ag}-\mathrm{BaO}_{2}$ catalyst in the absence of $\mathrm{Cl}$. The detrimental effect of too much alkali has been ascribed to increased isomerization of the epoxide $(7,100,98)$. Cesium adsorption to the $\operatorname{Ag}(111)$ face enhances the selectivity according to Campbell (77) and Grant and Lambert (78), again in certain coverage regimes. However, maximum selectivities reported are low compared to values found for silver in the presence of chlorine only.

These results imply that the classical theory of silver promotion (102) postulating a positive effect on the selectivity due to electronegative promotors has to be revised. In contradiction to this theory, electropositive elements, such as alkali, have been found to improve the selectivity at low conversion levels.

Also alloys have been investigated. Alloying of silver with palladium (103106) gives lower selectivities, probably because the palladium activates $\mathrm{C}-\mathrm{H}$ bond dissociation. Flank and Beachell (107) report initial increases in selectivity for gold alloys. However, Geenen et al. (108) showed for alloys with well-controlled surface composition a steady decline with gold dilution of silver. Whereas the selectivity for ethylene epoxidation steadily decreased, an increase in selectivity of propylene conversion was observed. At high dilution with gold a high selectivity toward acrolein was found. This is of interest because a low oxygen coverage of copper also yields acrolein with a high selectivity (109). Interestingly, Mazzocchia et al. (110) also report low selectivities of undoped silver for ethylene as well as propylene conversion. Some of the propylene, however, is converted to acrolein. They report that $\mathrm{Tl}_{2} \mathrm{O}_{3}$ gives propylene oxide with $16-35 \%$ selectivity. Similar selectivities are reported for ethylene epoxidation catalyzed by $\mathrm{Tl}$. 


\section{B. Total Oxidation of Ethylene}

Twigg (5) proposed that ethylene combustion occurs much faster than epoxide oxidation. He suggested that ethylene combustion occurs by reaction of two adsorbed oxygen atoms with the double bond of ethylene. This was based on the observed higher order in oxygen dependence of the total combustion rate versus that of epoxidation. Klugherz and Harriott (17) and Verma and Kaliagume (111) also reported a slightly higher order in oxygen for total combustion of ethylene versus epoxidation. Isotope experiments, replacing $\mathrm{C}_{2} \mathrm{H}_{4}$ by $\mathrm{C}_{2} \mathrm{D}_{4}(93,94,112)$, show that the rate-limiting step for ethylene combustion is $\mathrm{C}-\mathrm{H}$ bond breaking. This, however, does not exclude oxygen insertion into the $\mathrm{C}-\mathrm{C}$ double bond somewhere along the reaction path leading to total combustion.

Kagawa et al. $(81,82)$ and Grant and Lambert (94) compared $\mathrm{CO}_{2}$ production from ethylene combustion and ethylene epoxide combustion. The results of Kagawa $e t$ al. are presented in Table I. Whereas after ethylene adsorption $\mathrm{CO}_{2}$ formed by combustion desorbs at $423 \mathrm{~K}$, in the case of ethylene oxide adsorption on oxygen-covered silver the resulting $\mathrm{CO}_{2}$ desorbs at $463 \mathrm{~K}$. For the $\mathrm{Ag}(111)$ face Grant and Lambert relate a $\mathrm{CO}_{2}$ desorption peak at $\sim 380 \mathrm{~K}$ to combustion of adsorbed ethylene. They assign a $\mathrm{CO}_{2}$ desorption peak at $450 \mathrm{~K}$ to the decomposition of adsorbed ethylene oxide. These observations indicate that total oxidations of $\mathrm{C}_{2} \mathrm{H}_{4}$ and ethylene oxide proceed via different intermediates.

Kanno and Kobayashi (113) published results of pulsed reactions of ethylene and oxygen. They studied the carbonaceous residue formed on the catalyst after epoxide formation between 80 and $120^{\circ} \mathrm{C}$. Upon hydrogenation

TABLE I

Desorption Behavior of Various Gases Adsorbed on Oxygen-Preadsorbed Silver ${ }^{a}$

\begin{tabular}{lccccc}
\hline & & \multicolumn{2}{c}{$\begin{array}{c}\text { Desorption } \\
\text { temperature (K) }\end{array}$} & & $\begin{array}{c}\text { Dependence on } \\
\text { the amount } \\
\text { Adsorbate }\end{array}$ \\
\cline { 2 - 5 } & $\mathrm{C}_{2} \mathrm{H}_{4}$ & $\mathrm{C}_{2} \mathrm{H}_{4} \mathrm{O}$ & $\mathrm{CO}_{2}$ & $\mathrm{O}_{2}$ & $\begin{array}{c}\text { of preadsorbed } \\
\text { oxygen }\end{array}$ \\
\hline $\mathrm{C}_{2} \mathrm{H}_{4}$ & 334 & 334 & 423 & 503 & Bell shaped \\
$\mathrm{C}_{2} \mathrm{H}_{4} \mathrm{O}$ & $c$ & 330 & 463 & 503 & Bell shaped \\
$\mathrm{CO}_{2}$ & $d$ & $d$ & 383 & 503 & Linear \\
\hline
\end{tabular}

\footnotetext{
${ }^{a}$ From Ref. 82.

${ }^{b}$ This indicates the correlation between the amounts of oxygen preadsorbed and absorbate adsorbed later.

${ }^{c}$ Ethylene was not actually desorbed when ethylene oxide was adsorbed on oxygen-preadsorbed silver.

${ }^{d}$ There was no desorption.
} 
they found a product distribution similar to that observed after acetaldehyde oxidation. Acetic acid and ethanol are detected, strongly suggesting that acetaldehyde is formed as an intermediate. However, it cannot be ruled out that these intermediates were formed from the epoxide product. Force and Bell $(28,28 a, b)$ also proposed adsorbed acetaldehyde and acetate to be intermediates for the total combustion of ethylene. Their conclusion was based on in situ transmission infrared studies. Barteau et al. (114) showed on an $\mathrm{Ag}(110)$ face that acetaldehyde reacts with precovered oxygen to form stable carboxylate species. These species only decompose at room temperatures higher than $600 \mathrm{~K}$. Hence, they conclude that decomposition of adsorbed silver acetate species does not play a direct role in the reaction of total oxidation. In a later paper Sault and Madix (114a) report that adsorbed acetate can react with adsorbed oxygen to formate and $\mathrm{CO}_{2}$. The formate peak is found to decompose at $400 \mathrm{~K}$ to liberate $\mathrm{CO}_{2}$. At higher temperatures (around $580 \mathrm{~K}$ ) $\mathrm{CO}_{2}$ also desorbs as a result of acetate decomposition. Kobayashi (96) showed earlier that ethylene does not adsorb on a reduced silver catalyst, but does adsorb at $91^{\circ} \mathrm{C}$ on a catalyst precovered with oxygen. Similar results have been published by Campbell ( 86 ) and Grant and Lambert for silver single crystals. Campbell reports an increase in the heat of adsorption of ethylene from $8.9 \mathrm{kcal} / \mathrm{mol}$ on clean $\mathrm{Ag}(111)$ to $10.7 \mathrm{kcal} / \mathrm{mol}$ on oxygen-precovered silver.

Kagawa $e$ al. (81) showed that ethylene oxide and ethylene will desorb at $300 \mathrm{~K}$ from a silver catalyst precovered with oxygen. Vacant silver adsorption sites seem to be required for adsorption. On a completely covered silver catalyst no ethylene will adsorb at $298 \mathrm{~K}$ and a 300 -torr pressure.

$\mathrm{CO}_{2}$ and ethylene $(81,96)$ compete for adsorption to the oxygen-precovered surface, demonstrating that ethylene requires similar sites for adsorption as $\mathrm{CO}_{2}$. However, $\mathrm{CO}_{2}$, too, adsorbs at very high oxygen coverage, indicating that other adsorption sites are also available to $\mathrm{CO}_{2}$ or that there is a large difference in the conformation with respect to silver. The low order in ethylene partial pressure (17) also observed for the rate of total combustion suggests that indeed ethylene has to adsorb on the catalyst in the rate-limiting step. However, since this ethylene partial pressure dependence is very similar to the one found for the epoxidation reaction itself, Force and Bell's proposal $(28,28 a, b)$ implies a distinction between ethylene adsorbed on silver vacancies and ethylene adsorbed onto an oxidized silver surface, with the adsorbed oxygen not having silver vacancies as a neighbor.

In summary, the nonselective reaction of ethylene with the oxygen-covered silver surface occurs with $\mathrm{C}-\mathrm{H}$ bond breakage as the rate-limiting step. The resulting intermediate is rapidly converted to $\mathrm{CO}_{2}$ and $\mathrm{H}_{2} \mathrm{O}$ in view of the lower temperature of $\mathrm{CO}_{2}$ desorption in TPR experiments.

Little information on the reaction path of the intermediate generated after $\mathrm{C}-\mathrm{H}$ breakage is available. However, according to Kobayashi (113) and 
Force and Bell $(28,28 a, b)$ this intermediate is converted to the acetate and cannot be distinguished from the intermediates formed by acetaldehyde oxidation. However, it cannot be ruled out that these intermediates are due to consecutive reactions of adsorbed epoxide proceeding during preconditioning of the catalyst. Data from Kagawa et al. (81) and Grant and Lambert (94) indeed indicate different reaction paths for epoxide and ethylene combustion. Sault and Madix's data (114a) suggest that the low-temperature $\mathrm{CO}_{2}$ desorption observed upon adsorption of ethylene to silver covered with a preadsorbed oxygen layer is due to formate decomposition.

\section{Reactions of Ethylene Oxide and Acetaldehyde}

Ethylene oxide does not adsorb to the oxygen-free surface at room temperature. Preadsorption of oxygen increases the heat of adsorption of ethylene oxide from 8.5 to $12.5 \mathrm{kcal} / \mathrm{mol}$ (113a); its temperature of desorption becomes $335 \mathrm{~K}$, comparable to that of ethylene at these conditions. In the absence of preadsorbed oxygen, ethylene oxide decomposes on silver into ethylene and adsorbed oxygen. This has already been reported by Twigg (5) and Kenson and Lapkin (6). Part of the ethylene oxide is also converted to acetaldehyde. A typical result for silver powder is shown in Fig. 13. On the other hand, preadsorption of oxygen onto $\mathrm{Ag}$ suppresses acetaldehyde formation more than ethylene oxide decomposition. This is demonstrated by an experiment at $200^{\circ} \mathrm{C}$ similar to that of Fig. $13 \mathrm{~A}$, but now in the presence of $\mathrm{CO}$. The oxygen deposited by ethylene oxide decomposition is continuously removed by $\mathrm{CO}$ as $\mathrm{CO}_{2}$. Acetaldehyde does not react with oxygen-free silver powder. However, at room temperature it rapidly adsorbs to silver with a preadsorbed oxygen layer. Also, according to Kanno and Kobayashi (113), at comparable conditions a carbonaceous residue formed. Barteau et al. (114) found acetic acid to desorb around $300^{\circ} \mathrm{C}$ and part of it is found to decompose to methane. Kanno and Kobayashi also observed these intermediates using diffuse reflectance infrared Fourier transform (DRIFT) spectroscopy.

A difficulty with the evaluation of literature data is that often studies have been made of supported silver. The support may have some activity of itself; the reaction affected will be the isomerization of epoxide to acetaldehyde. At $200^{\circ} \mathrm{C}$ without oxygen in the gas phase (6), complete conversion of ethylene oxide in the gas phase gave a product ratio $\mathrm{CH}_{3} \mathrm{CHO}: \mathrm{C}_{2} \mathrm{H}_{4}: \mathrm{CO}_{2}=3: 1: 1.2$. In the presence of excess oxygen only total oxidation of ethylene oxide is found. Prauser et al. (6a), however, find for a supported catalyst that in excess oxygen $\left(\mathrm{O}_{2}: \mathrm{C}_{2} \mathrm{H}_{4} \mathrm{O}=50\right)$ and in the presence of ethylene a significant amount of acetaldehyde is formed, which even at $270^{\circ} \mathrm{C}$ is only very slowly converted. The authors suggest that a feed also containing ethylene blocks the 


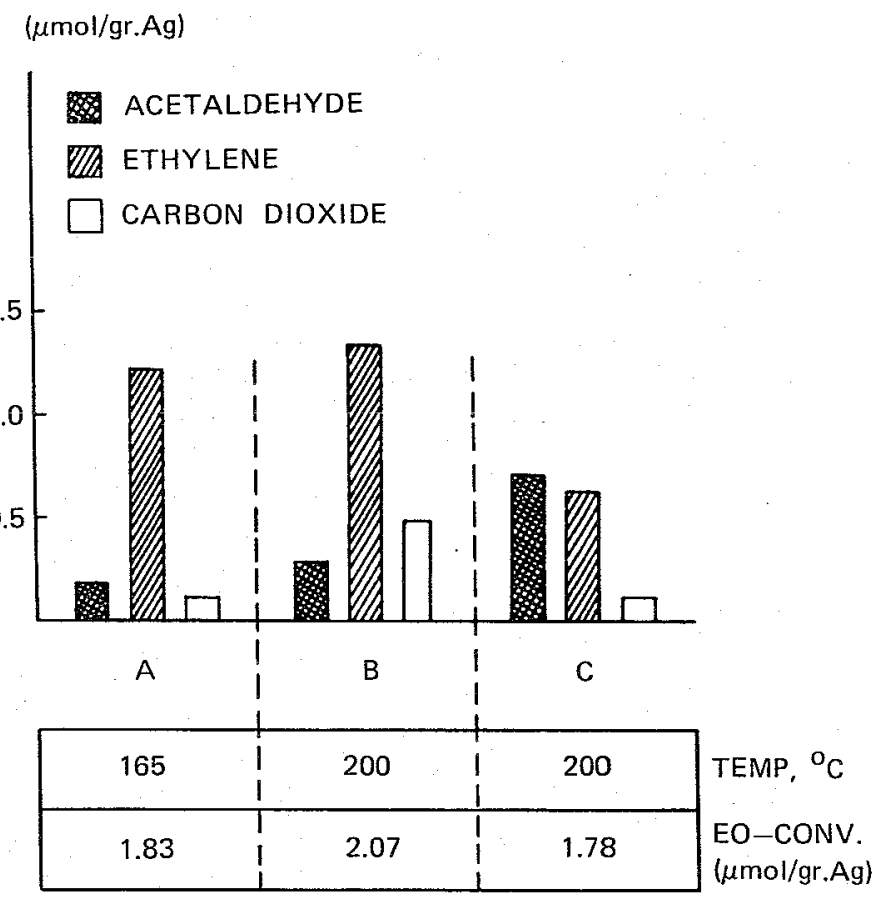

FIG. 13. Influence of surface oxygen on ethylene oxide conversion products (117). Initial conditions: (A) 5.4 torr EO; (B) 5.5 torr $\mathrm{EO}+$ preadsorbed $\mathrm{O}_{2}$; (C) 5.4 torr $\mathrm{EO}+8.9$ torr $\mathrm{CO}$.

sites on the silver surface where ethylene oxide isomerizes, since in parallel investigations on the partial oxidation of ethylene to ethylene oxide on the same catalyst only traces of acetaldehyde were found.

Süptitz and Kripylo (7) suggest that ethylene oxide isomerization preferentially occurs at steps and kink sites. Later single-crystal work, however, seems to refute this (78).

According to Kenson and Lapkin (6) the rate of ethylene oxide isomerization on silver is first order in ethylene oxide with an activation energy of $9.8 \mathrm{kcal} / \mathrm{mol}$. Ethylene oxide adsorption is rate limiting. In the presence of gasphase oxygen, acetaldehyde is rapidly oxidized to carbon dioxide and water between 200 and $285^{\circ} \mathrm{C}$. Kenson and Lapkin $(\sigma)$ report, at $200^{\circ} \mathrm{C}$ for ethylene oxide conversion, a rate constant of the order of $10^{-4} \mathrm{~s}^{-1}$, whereas the rate constant for ethylene oxide formation from ethylene is of the order of $10^{2} \mathrm{~s}^{-1}$ under conditions where it is first order in oxygen partial pressure and zero order in ethylene partial pressure. Under these conditions the activation energies for epoxide formation and combustion of ethylene oxide are 21.4 and $29 \mathrm{kcal} / \mathrm{mol}$, respectively. 
The result that ethylene oxide combustion by silver proceeds via acetaldehyde formation agrees with Kanno and Kobayashi's (113) data indicating the same intermediates on a catalyst active in ethylene epoxide formation and as formed upon adsorption of acetaldehyde.

It has also been found by Stoukides and Vayenas (115) and Kanoh et al. (116) that over supported catalysts ethylene oxide is combusted more slowly than ethylene. One concludes that direct ethylene oxide conversion by the silver surface itself at practical conditions appears negligible. Ethylene oxide isomerization by the silver surface appears to be suppressed by the presence of oxygen.

Grant and Lambert (8) studied ethylene oxide isomerization catalyzed by the $\operatorname{Ag}(111)$ face. They report that at temperatures below $410 \mathrm{~K}$ isomerization of ethylene oxide is rate limiting, whereas at higher temperatures adsorption of ethylene oxide becomes rate determining. They report that the presence of dissolved oxygen positively influences the rate of isomerization. Preadsorption of Cs strongly suppresses the isomerization rate.

Comparison of data on the conversion of ethylene epoxide and acetaldehyde has to be done with care. At temperatures lower than $200^{\circ} \mathrm{C}$ and low partial pressures of oxygen, acetaldehyde rapidly forms an adsorbed layer of carbonaceous residue, which limits acetaldehyde and oxygen adsorption to a small fraction of the surface. Acetaldehyde conversion is low because acetate formed from it only decomposes above a temperature in the order of $230^{\circ} \mathrm{C}$. In the absence of acetaldehyde, but at the same conditions, it has been found that ethylene oxide oxidation is one order of magnitude faster than acetaldehyde conversion (117), because a carbonaceous layer is formed much less rapidly and apparently it decomposes to $\mathrm{CO}_{2}$ at lower temperatures.

It appears therefore that ethylene oxide can be oxidized by silver following two reaction paths: one proceeds via isomerization to acetaldehyde and consecutive combustion; the other proceeds directly, probably via the same intermediate that leads to decomposition of the epoxide to ethylene.

Ethylene oxide isomerization as well as decomposition becomes suppressed at high oxygen coverage. The rate of ethylene oxide adsorption also strongly decreases and decomposition of ethylene oxide to ethylene and adsorbed oxygen becomes thermodynamically unfavorable (see Section IV). Indeed, at higher temperature and oxygen partial pressure catalysts supported by a lowsurface-area inert support have rate constants $k_{3}$ much smaller than $k_{2}$.

\section{Summary OF THE Kinetics OF THE Ethylene Epoxidation Reaction}

At low conversion, $k_{1}$, the rate of epoxidation, and $k_{2}$, the rate of ethylene combustion, determine the selectivity. The ratio $k_{1} / k_{2}$ depends strongly on the 
presence of moderators and possibly on the presence of promotors as well. Since the best selectivities measured are between 80 and $90 \%$, the value of $k_{2}$ for an optimized catalyst is approximately one-sixth that of $k_{1}$. The dependence of $k_{2}$ on the partial pressure of $\mathrm{O}_{2}$ is stronger than that of $k_{1}$; the limiting order of the partial pressure in ethylene is zero. Most authors find that the activation energies are equal or that the activation energy for $k_{2}$ is slightly higher than that for $k_{1}$. At higher conversion, consecutive reaction of ethylene oxide may become important. Direct participation of silver in this reaction depends greatly on the state of the silver surface, which is determined by temperature, gas phase partial pressures, and the presence of promotors. No complete studies of ethylene oxide conversion in the presence of chlorine are available. Published data are consistent with the view that ethylene oxide isomerization or decomposition is slow on a silver surface under epoxidation conditions. However, acetaldehyde may be formed on the carrier of supported catalysts. At catalytic conditions acetaldehyde adsorbs strongly onto oxygencovered silver and is more rapidly converted to $\mathrm{CO}_{2}$ and $\mathrm{H}_{2} \mathrm{O}$ than ethylene by one order of magnitude. There is no information on the effect of moderators or promotors on the conversion of acetaldehyde.

Catalysts used in the 1960 s had a $k_{3} \ll k_{2}$. Modern catalysts show a stronger dependence of the selectivity on conversion, indicating that $k_{3}$ has increased. Information on the relative magnitude of $k_{3}$ versus $k_{2}$ is scant. The conclusion of Süptitz and Kripylo (7), that acetaldehyde reacts much faster than ethylene with adsorbed oxygen, agrees with the estimate mentioned above that the reaction of adsorbed oxygen with ethylene to epoxide should be a factor of 10 slower than that of acetaldehyde. Süptitz and Kripylo (7) find that as a result the presence of acetaldehyde changes $k_{1} / k_{2}$. This implies a significant modification of Scheme 1 at conditions where $k_{3}$ becomes significant, because $k_{1} / k_{2}$ is apparently a function of very low concentrations of acetaldehyde formed in the consecutive reaction of ethylene oxide.

\section{The Mechanism of Ethylene Epoxidation}

\section{A. Atomic Versus Molecular Oxygen: Heterogeneous Catalysis}

If one supposes that only molecularly adsorbed oxygen can give epoxide upon reaction with ethylene, six molecules of oxygen can produce six molecules of ethylene epoxide. Because only one atom per oxygen molecule becomes incorporated into epoxide, six atoms will remain adsorbed onto the silver surface. If one excludes the possibility of recombination, ethylene 
molecules will have to be used to remove atomic oxygen in a nonselective reaction. Six oxygen atoms are needed for total oxidation of ethylene. This argument leads to the prediction of a maximum initial selectivity of $6 / 7$, if molecular oxygen provides the reaction path to the epoxide.

Few data $(I c, 25)$ have been reported on selectivities larger than $6 / 7$, one of the main reasons why this mechanism has found wide support $(1,10)$.

Kilty et al. (23) studied the interaction of oxygen and ethylene with a silver catalyst surface by infrared spectroscopy and used the moderating effect of chlorine adsorption to establish its influence on oxygen chemisorption. The infrared studies presented in Fig. 14 confirmed the earlier Russian work (24). Ethylene and oxygen adsorption at $95^{\circ} \mathrm{C}$ on silver produced a complex containing molecular oxygen with vibration frequency at $860 \mathrm{~cm}^{-1}$. This was confirmed using isotope substitution of oxygen. The complex decomposed at $110^{\circ} \mathrm{C}$. These results were highly indicative of the formation of an ethylene$\mathrm{O}_{2}$ intermediate. However, no $\mathrm{C}-\mathrm{O}$ frequencies could be detected.

Three distinct $\mathrm{O}_{2}$ adsorption processes with apparent activation energies of $<10,33$, and $60 \mathrm{~kJ} / \mathrm{mol}$ were observed. Preadsorption of chlorine reduces the amount of oxygen adsorbed significantly. As shown in Fig. 15, at low chlorine coverage the rate of adsorption into the state with a low activation energy is more affected than the rate of adsorption into the one with the activated adsorption. At $\mathrm{Cl}$ coverages exceeding one $\mathrm{Cl}$ per four $\mathrm{Ag}$ atoms, the activated process became also inhibited, each chlorine now blocking adsorption of one oxygen molecule. Kilty et al. concluded that the process with an activation energy of $<10 \mathrm{~kJ} / \mathrm{mol}$ is related to dissociative adsorption, requiring ensembles consisting of four silver atoms, while the process with an activation energy of $33 \mathrm{~kJ} / \mathrm{mol}$ was ascribed to the nondissociative adsorption of $\mathrm{O}_{2}$. This seminal work generated much research to verify or expand the ideas proposed.

Force and Bell $(28,28 a, b)$ studied by infrared spectroscopy a silicasupported silver catalyst placed in an in situ absorption cell under catalytic conditions. Since they did not observe an intermediate with molecular oxygen, they assumed, in agreement with Twigg's proposals, that adsorbed atomic oxygen was the species active in the epoxidation reaction. According to Force and Bell the chlorine effect can be explained by postulating that $\mathrm{C}-\mathrm{H}$ activation requires ethylene to be adsorbed to silver vacancies. As a result, a low oxygen coverage leads to total combustion. Chlorine adsorption suppresses the occurrence of silver surface vacancies and hence the selectivity for epoxidation increases.

The oxygen adsorption data by Kilty et al. (23) can only be reconciled with Force and Bell's postulates, if the heat of adsorption of atomic oxygen is a strong function of oxygen coverage and chlorine has a significant effect on it. Czanderna (118) measured the adsorption isotherms of silver powder between 


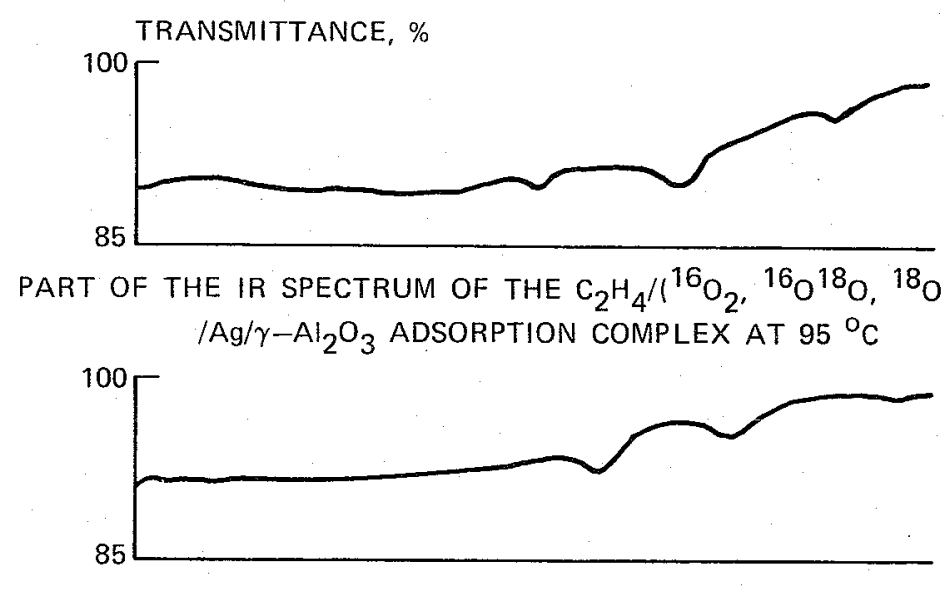

DITTO AFTER HEATING TO $110^{\circ} \mathrm{C}$

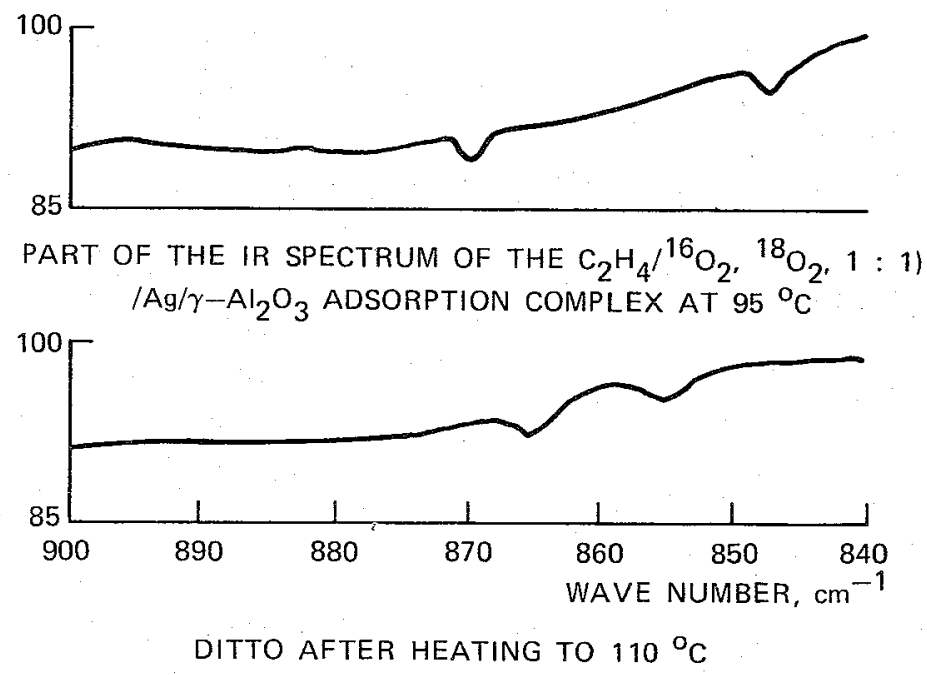

FIG. 14. IR spectra of $\mathrm{C}_{2} \mathrm{H}_{4}$ /oxygen adsorption complexes (23).

450 and $615 \mathrm{~K}$ at oxygen pressures of $0.2-40 \mathrm{kPa}$ using a gravimetric technique. From the isotherms he derived the isosteric heat of adsorption. The heat of adsorption of $\mathrm{O}_{2}$ equals $176 \mathrm{~kJ} / \mathrm{mol}$ up to a surface coverage of $\mathrm{O}_{\mathrm{s}} / \mathrm{Ag}_{\mathrm{s}}=0.5\left(\mathrm{Ag}_{\mathrm{s}}\right.$ is the number of silver surface atoms, and $\mathrm{O}_{\mathrm{s}}$ the number of adsorbed oxygen atoms). In the region $0.5<\mathrm{O}_{\mathrm{s}} / \mathrm{Ag}_{\mathrm{s}}<1$ the heat of adsorption equals $74 \mathrm{~kJ} / \mathrm{mol}$. At higher coverage he finds a mild increase in heat of adsorption, which he ascribes to adsorption of molecular oxygen. 


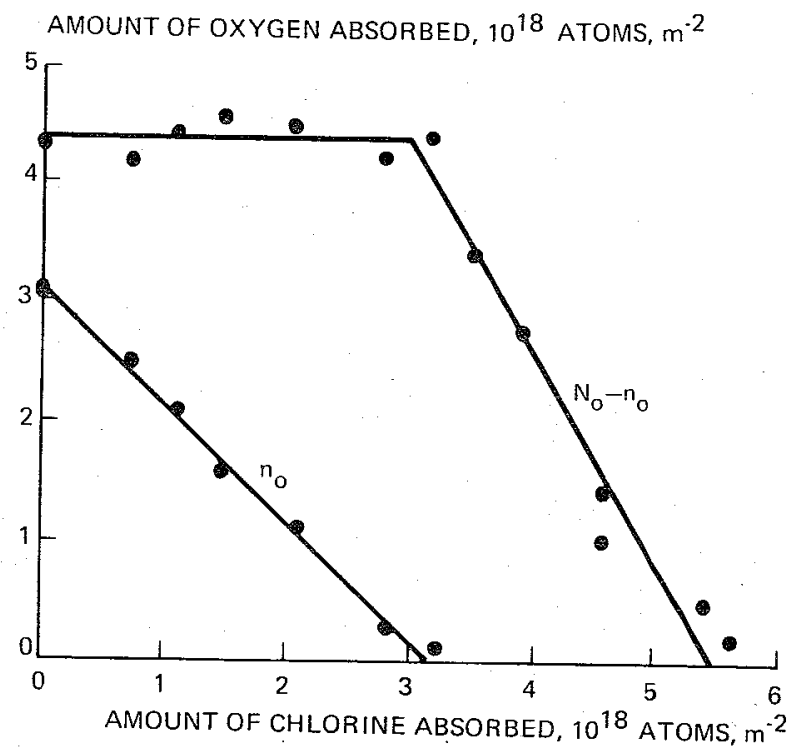

FIG. 15. Correlation between the amount of chlorine preadsorbed and the amounts of oxygen subsequently adsorbed at $373 \mathrm{~K}$ by a nonactivated process $\left(n_{0}\right)$ and by an activated process $\left(N_{0}-n_{0}\right)(12)$.

The data by Force and Bell do not reject the possibility that epoxide is formed by rapid reaction of ethylene with molecular oxygen as precursor state, as suggested by Prince et al. (119) and Haul et al. (120).

According to Park et al. (25) weakly adsorbed oxygen is required for high selectivity. A similar conclusion had been derived earlier by Mikami et al. (12I), who also found that oxygen weakly adsorbed to the silver surface at high coverage selectively yields epoxide upon reaction with ethylene. Carbon dioxide adsorbs to strongly adsorbed oxygen formed at lower coverage, the kind of oxygen that leads to total combustion. This explains the favorable effect of $\mathrm{CO}_{2}$ adsorption upon the epoxidation selectivity.

Tanaka and Yamashina (122) compared the reactivity of $\mathrm{Ag}_{2} \mathrm{O}$ and $\mathrm{AgO}$ with ethylene. This is of interest, because the surface stoichiometry of the catalytically active phase is closer to $\mathrm{AgO}$ than $\mathrm{Ag}_{2} \mathrm{O}$. Thermal desorption of oxygen occurs at two temperatures (see Fig. 16). Upon reaction the lowtemperature peak appears to have disappeared. Tanaka and Yamashina showed that this decrease in oxygen concentration could also be observed from the EPR signal of $\mathrm{O}_{2}^{-}$. Kagawa et al. (123) showed that epoxide was formed in the reaction of ethylene with $\mathrm{AgO}$.

$\mathrm{O}_{2}^{-}$signals had been observed earlier on the surface of Vycor quartz glass, by Clarkson and Cirillo (124). They calculated that only $0.02 \%$ of the 

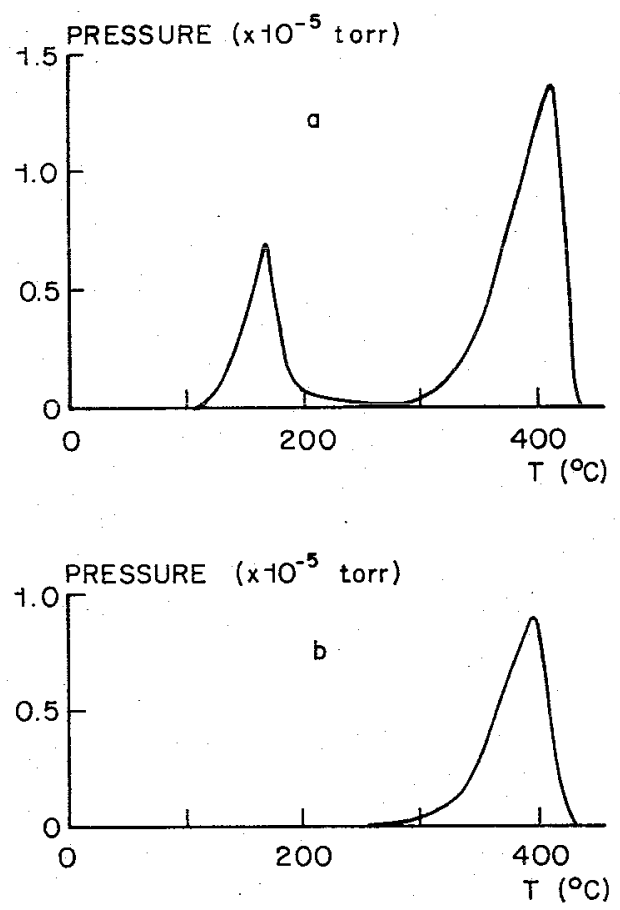

FIG. 16. Thermal desorption curves of oxygen: (a) AgO sample; (b) AgO sample after reaction with ethylene ( 40 torr) at $100^{\circ} \mathrm{C}$ for 4 days (122).

adsorbed oxygen could be responsible for the signal. However, it can be calculated from the data of Backx et al. (89) that at least $10 \%$ of the adsorbed oxygen can become incorporated into ethylene as the epoxide, strongly indicating that atomic oxygen is responsible. The data by Tanaka are consistent in that they show that weakly adsorbed oxygen yields epoxide.

Single-crystal studies discussed in Section II reveal that in the absence of coadsorbates oxygen adsorbs only in molecular form at low temperatures ( 36 , $43,125,126)$. At temperatures higher than $380 \mathrm{~K}$ on $\mathrm{Ag}(111)$ or $215 \mathrm{~K}$ on $\operatorname{Ag}(110)$, it desorbs or dissociates into atomic oxygen. On single crystals the maximum $\mathrm{O}_{\mathrm{s}} / \mathrm{Ag}_{\mathrm{s}}$ ratio reached under conventional UHV conditions at the external part of the surface equals approximately 0.5 . This is considerably lower than the amount of oxygen required for optimum selectivity on silver catalysts. However, oxygen-isotope studies have shown that an $\mathrm{Ag}(110)$ singlecrystal face, having undergone exposure to oxygen and subsequent oxygen desorption by temperature-programmed desorption at $T<700 \mathrm{~K}$, so that by HREELS no oxygen can yet be observed (127), residual oxygen has been left in subsurface positions. If in a consecutive experiment ${ }^{18} \mathrm{O}_{2}$ is adsorbed onto $\mathrm{Ag}$, 
the oxygen adsorbed in a previous experiment reappears upon thermal desorption, because it exchanges with adsorbed oxygen on the surface. The thermal desorption peak at $320^{\circ} \mathrm{C}$ now appears as ${ }^{16} \mathrm{O}_{2}$ and ${ }^{18} \mathrm{O}_{2}$ (see Fig. 17). Very much the same results have been found by Kagawa et al. $(81,82)$ in similar $\mathrm{O}_{2}$-isotope-exchange experiments. They found on reduced silver powder that a fair amount of oxygen exists on or in silver that cannot be removed from the sample upon hydrogen treatment at $623 \mathrm{~K}$.

The preconditioning method used by Grant and Lambert $(49,90)$ to make their $\mathrm{Ag}(111)$ face epoxidation selective probably introduces subsurface oxygen so that in the catalytic experiment $\mathrm{O}_{\mathrm{s}} / \mathrm{Ag}_{\mathrm{s}} \gg 0.5$. Bowker $(128)$ and Campbell (125) have shown that also on single-crystal surfaces the bond strength of oxygen decreases at $\mathrm{O}_{\mathrm{s}} / \mathrm{Ag}$ ratios higher than 0.5 . Tan et al. (87) have found that subsurface oxygen only desorbs from the $\mathrm{Ag}(111)$ face
at $850 \mathrm{~K}$.

As discussed earlier, Campbell and Paffett $(85,86)$ and Tan et al. $(87)$ have studied the effect of preadsorbed chlorine on the catalytic activity of silver single-crystal faces. Campbell (86) found that the steady-state oxygen coverage, measured by TPD after reactor runs, decreased rapidly with chlorine coverage (see Fig. 11). However, no oxygen was found when the chlorine coverage exceeded $50 \%$ of its maximum value. A similar result is found by Tan et al. (87). However, Tan et al. also measured the maximum amount of oxygen that can be adsorbed as a function of chlorine concentration and they concluded that oxygen adsorption is impossible only if $\theta_{\mathrm{Cl}}=100 \%$.

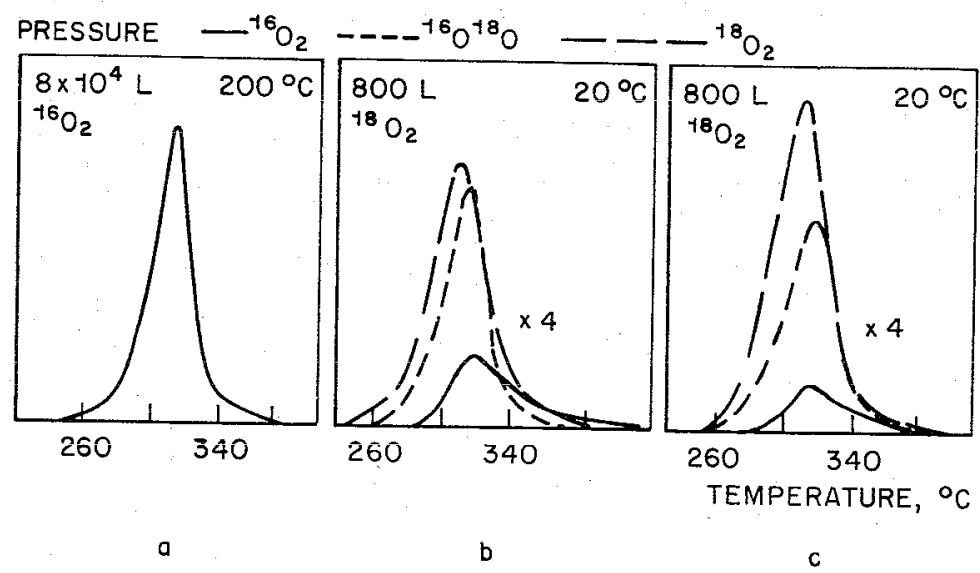

FIG. 17. Temperature-programmed desorption spectra (heating rate $4.6^{\circ} \mathrm{C} / \mathrm{s}$ ): (a) after exposure to $8 \times 10^{4} \mathrm{~L}^{16} \mathrm{O}_{2}$ at $200^{\circ} \mathrm{C}$; (b and c) after subsequent exposure to $800 \mathrm{~L}^{18} \mathrm{O}_{2}$ at
$20^{\circ} \mathrm{C}(126)$. 
These observations are of interest, since the postreactor oxygen data appear to indicate that no correlation can exist between adsorbed atomic oxygen and epoxidation selectivity, because no adsorbed oxygen is found at chlorine concentrations where the selectivity is high. This issue raises the question whether reaction of ethylene with preadsorbed oxygen is just an interesting stoichiometric reaction, or whether it has a direct bearing on the catalytic event. Campbell (86) initially proposed that his results indicated that a precursor molecular oxygen species is responsible for the selective epoxidation reaction.

In order to study the relative rates of preadsorbed oxygen versus impinging oxygen molecules from the gas phase onto the silver surface with ethylene, Van Santen and De Groot (129) studied the epoxidation of ethylene with ${ }^{16} \mathrm{O}$ species adsorbed onto the silver surface, but with varying concentrations of ${ }^{18} \mathrm{O}_{2}$ in the gas phase. The experiments were done in a recirculation apparatus. Figure 18 shows a typical result for an experiment with no oxygen in the gas phase. The $\mathrm{O}_{2}$ is preadsorbed onto $\mathrm{Ag}$ at $200^{\circ} \mathrm{C}$ and 10 -torr $\mathrm{O}_{2}$ in order to produce $\mathrm{O}_{\mathrm{s}} / \mathrm{Ag}_{\mathrm{s}} \sim 1$. After evacuation, ethylene (13 torr) is added at room temperature and the formation of epoxide and $\mathrm{CO}_{2}$ is studied as a function of temperature. Epoxide formation already occurs at relatively low temperatures. This continues until all preadsorbed oxygen has been removed from

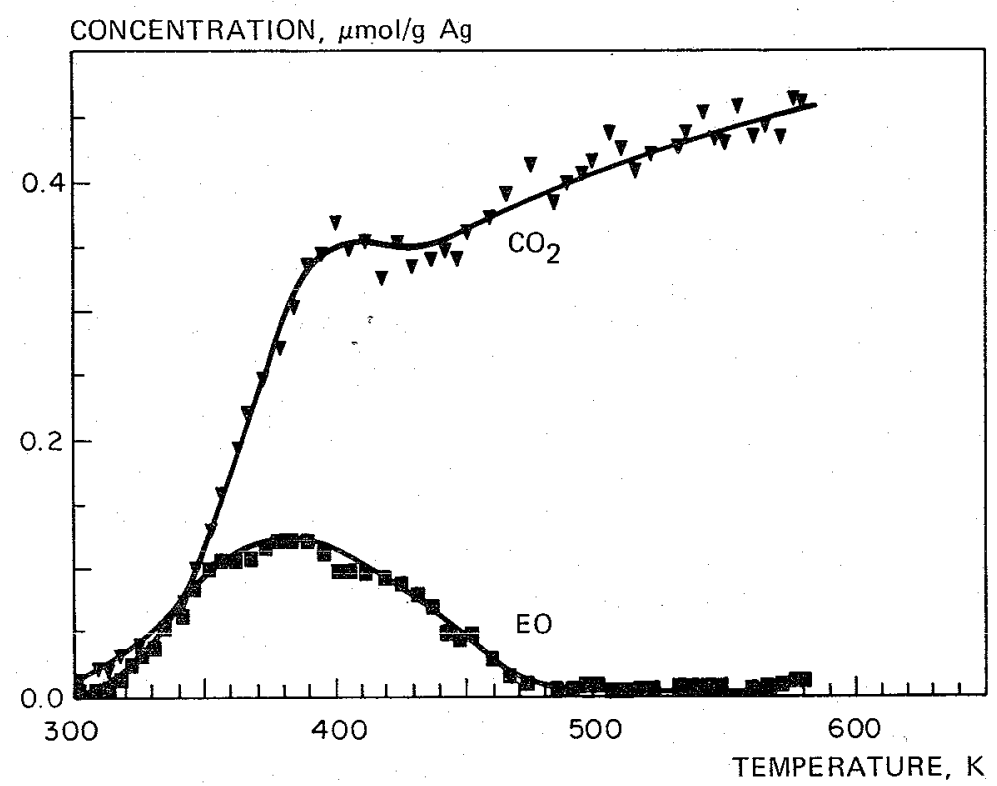

Fig. 18. Experiment 1. Production of $\mathrm{EO}$ and $\mathrm{CO}_{2}$ as a function of temperature. Initial ethylene pressure, 13 torr (129). 
the silver powder. The epoxide concentration decreases, because the compound decomposes back into adsorbed oxygen and ethylene.

As epoxide formation occurs at temperatures below the temperature at which isotope exchange between ${ }^{16} \mathrm{O}_{2}$ and ${ }^{18} \mathrm{O}_{2}$ is rapid (130), an experiment with ${ }^{18} \mathrm{O}_{2}$ in the gas phase seemed useful. Figure 19 shows the yield of $\mathrm{E}^{18} \mathrm{O}$ and $\mathrm{E}^{16} \mathrm{O}$ as a function of time in an experiment very similar to the previous one, starting with the silver surface precovered with ${ }^{16} \mathrm{O}$ with $\mathrm{O}_{\mathrm{s}} / \mathrm{Ag}_{\mathrm{s}} \sim 1$. However, this time, together with the ethylene (13 torr), 20 torr of ${ }^{18} \mathrm{O}_{2}$ had been added to the gas phase. It was observed that $\mathrm{E}^{16} \mathrm{O}$ is formed earlier than $\mathrm{E}^{18} \mathrm{O}$. This definitely proves that epoxide formation occurs not from a precursor state, but by reaction with adsorbed oxygen.

Table II gives the maximum amounts of $\mathrm{E}^{16} \mathrm{O}$ found for five experiments. The experiment with no oxygen in the gas phase, the one with 2-torr ${ }^{18} \mathrm{O}_{2}$ in the gas phase, and another experiment with 20 -torr ${ }^{18} \mathrm{O}_{2}$ in the gas phase are numbered 1,2 , and 3, respectively. One observes an increase in the amount of $\mathrm{E}^{16} \mathrm{O}$ formed with increasing ${ }^{18} \mathrm{O}_{2}$ gas-phase pressure. This unexpected phenomenon appears to be due to the presence of ${ }^{16} \mathrm{O}$ in a subsurface layer, not accessible to ethylene. However, this subsurface ${ }^{16} \mathrm{O}$ rapidly interchanges with surface oxygen. With increasing gas pressure more epoxide is formed, because more ${ }^{18} \mathrm{O}_{2}$ is available and hence more ${ }^{18} \mathrm{O}$ becomes adsorbed onto the silver surface. As a result, more complete exchange with subsurface ${ }^{16} \mathrm{O}$ atoms is possible and more $\mathrm{E}^{16} \mathrm{O}$ is formed.

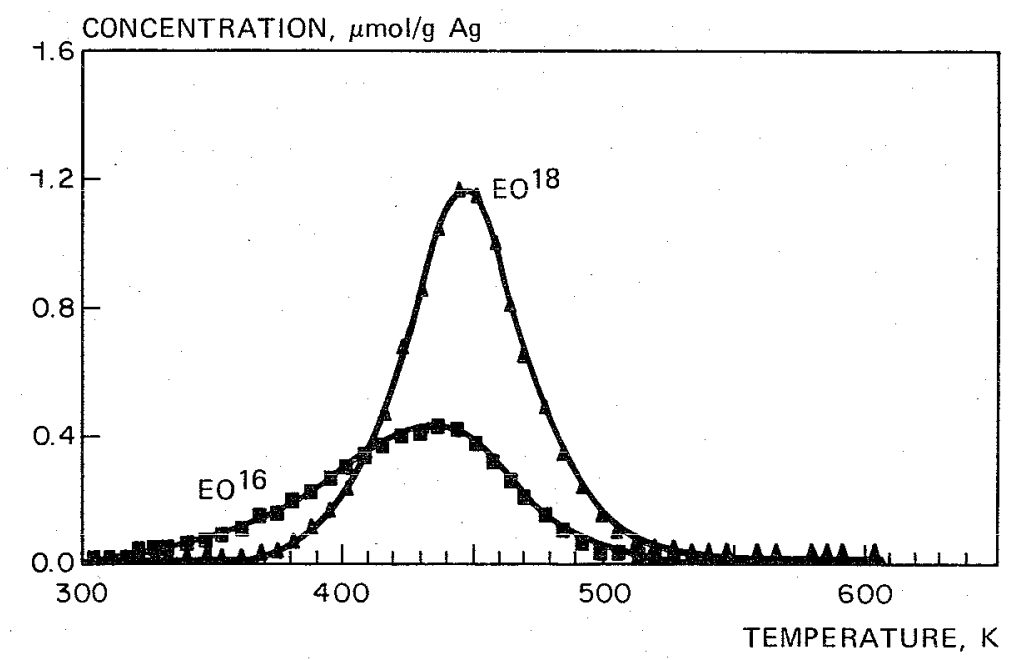

FIg. 19. Experiment 3. Initial gas-phase ${ }^{18} \mathrm{O}_{2}$ pressure, 20.4 torr; initial ethylene pressure, 13 torr; ${ }^{16} \mathrm{O}_{2}$ preadsorbed, $1.08 \mu \mathrm{mol} / \mathrm{g} \mathrm{Ag} ; \mathrm{E}^{16} \mathrm{O}$ and $\mathrm{E}^{18} \mathrm{O}$ production as a function of temperature $(I 29)$. 
TABLE II

Summary of $\mathrm{E}^{16} \mathrm{O}$ Formation and ${ }^{16} \mathrm{O}_{2}$ Incorporation ${ }^{a}$

\begin{tabular}{ccccc}
\hline Expt. & $\begin{array}{c}{ }^{16} \mathrm{O}_{2} \text { preads. } \\
(\mu \mathrm{mol} / \mathrm{g} \mathrm{Ag})\end{array}$ & $\begin{array}{c}{ }^{18} \mathrm{O}_{2} \text { initial } \\
\text { gas pressure } \\
\text { (torr) }\end{array}$ & $\begin{array}{c}\text { Maximum } \mathrm{E}^{16} \mathrm{O} \\
\text { produced } \\
(\mu \mathrm{mol} / \mathrm{g} \mathrm{Ag})\end{array}$ & $\begin{array}{c}{ }^{16} \mathrm{O}_{2} \text { incorporated } \\
(\mu \mathrm{mol} / \mathrm{g} \mathrm{Au})\end{array}$ \\
\hline 1 & 1.09 & - & 0.12 & 0.51 \\
2 & 0.94 & 2.6 & 0.19 & 0.43 \\
3 & 1.08 & 20.4 & 0.42 & 0.9 \\
4 & 0.46 & 20.4 & 0.12 & 0.28 \\
5 & 0.46 & - & - & 0.03 \\
\hline
\end{tabular}

${ }^{a}$ From Ref. 129 . Note: Total number of silver surface atoms $=2 \mu$ atom $/ \mathrm{g} \mathrm{Ag} ; 1$ torr $=0.58$ $\mu \mathrm{mol} / \mathrm{g} \mathrm{Ag}$.

${ }^{b}$ Measured at a temperature where $\mathrm{E}^{16} \mathrm{O}$ production is maximum.

That this phenomenon indeed occurs had been shown in an experiment where the $\mathrm{Ag}$ powder had been prepared in a state containing only subsurface oxygen (experiments 4 and 5 in Table II). This can be done by removal of half of the oxygen layer of a silver powder with $\mathrm{O}_{\mathrm{s}} / \mathrm{Ag}_{\mathrm{s}} \sim 1$ by thermal desorption at $320^{\circ} \mathrm{C}$. If one studies the amount of oxygen that can be adsorbed onto a silver powder in this state, it appears that only half of the maximum quantity will adsorb. This is illustrated in Fig. 20.

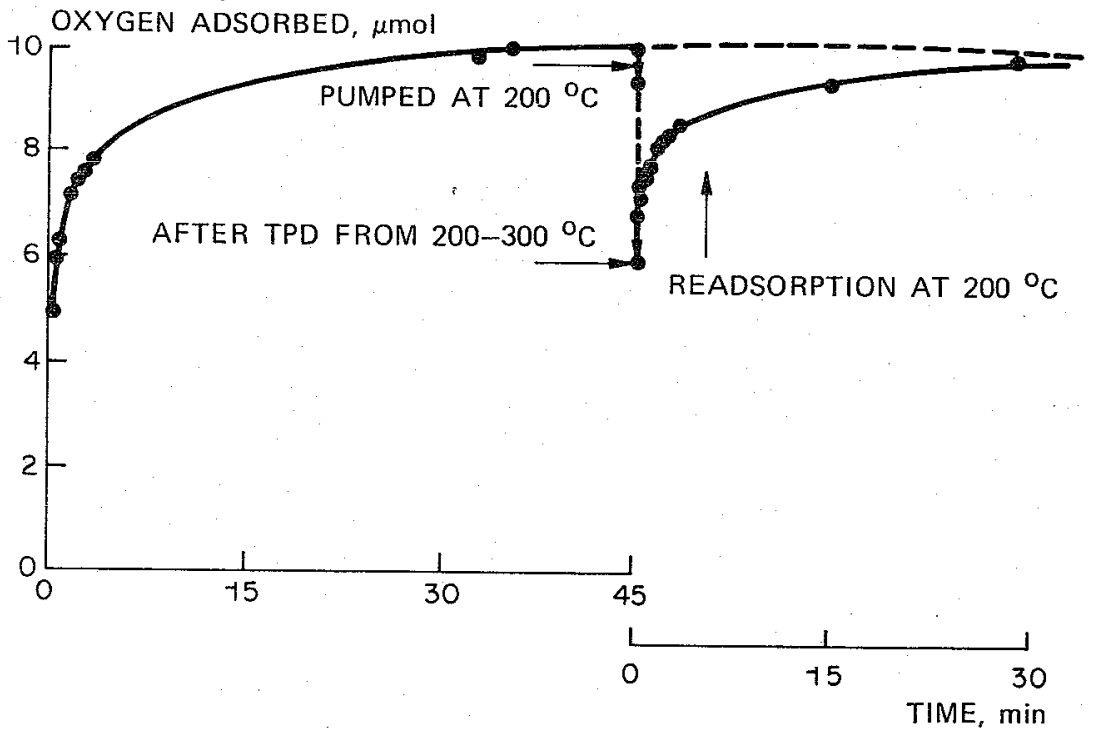

Fig. 20. Amount of oxygen adsorbed as a function of time and temperature (89). 


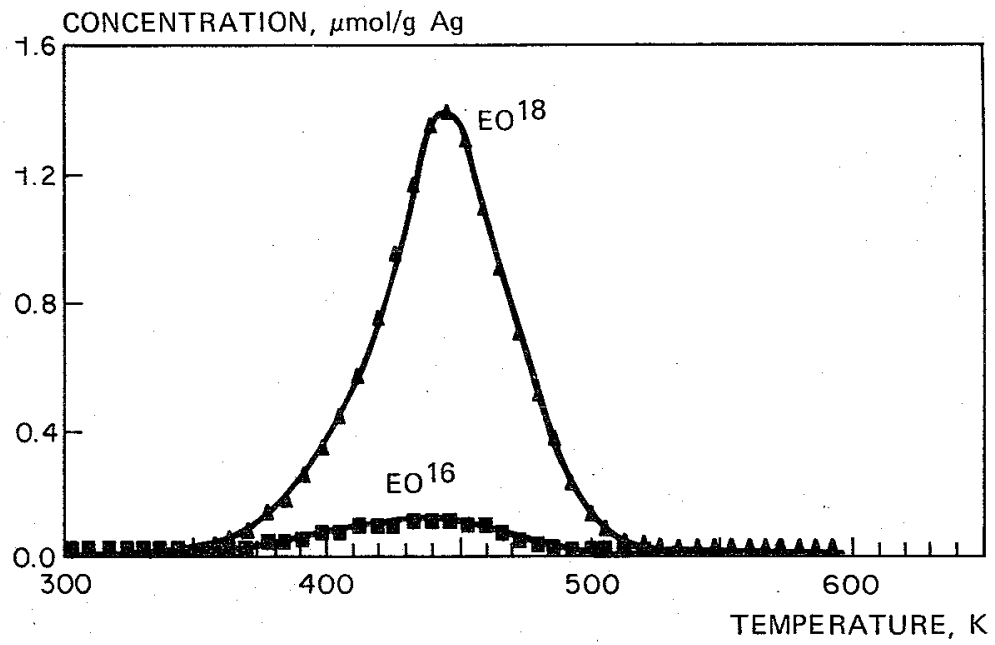

FIG. 21. Initial gas-phase ${ }^{18} \mathrm{O}_{2}$ pressure, 20.4 torr; initial ethylene pressure, 13 torr; ${ }^{16} \mathrm{O}_{2}$ preadsorbed, $0.46 \mu \mathrm{mol} / \mathrm{g} \mathrm{Ag}$; only subsurface oxygen present $(129) ; \mathrm{E}^{16} \mathrm{O}$ and $\mathrm{E}^{18} \mathrm{O}$ production as a function of temperature.

If one studies the amount of $\mathrm{E}^{16} \mathrm{O}$ and $\mathrm{E}^{18} \mathrm{O}$ formed upon exposure of a silver powder containing only subsurface oxygen, with 20-torr ${ }^{18} \mathrm{O}_{2}$ and 13torr ethylene (Fig. 21), it is seen that $\mathrm{E}^{16} \mathrm{O}$ and $\mathrm{E}^{18} \mathrm{O}$ appear at the same time. Adsorption of gas-phase oxygen is needed to create surface oxygen accessible to ethylene for reaction. Exchange between surface oxygen and subsurface oxygen appears rapid compared to the rate of reaction with ethylene.

The results are summarized in Table II. No epoxide is formed in the last experiments if no gas-phase oxygen is present, proving that subsurface oxygen is inaccessible to ethylene.

These experiments demonstrate that oxygen atoms can become incorporated into ethylene as the epoxide. Of the subsurface oxygen, $10 \%$ is found back in the epoxide. One cannot preclude recombination of oxygen atoms in the transition state giving epoxide, but this is unlikely in view of the low temperature at which epoxide formation can occur. Laser Raman experiments performed to define the oxygen species at the silver powder surface did not indicate the presence of adsorbed $\mathrm{O}_{2}^{-}$species (131).

\section{B. The Issue of Atomic versus Molecular Oxygen: HOMOGENEOUS REACTIONS}

Hydroperoxides are well-known oxidation agents that produce epoxides upon reaction with ethylene (132). This is in line with the proposal that adsorbed molecular oxygen produces ethylene oxide by reaction with 
ethylene. Usually an acid catalyst is needed for the reaction to proceed. One oxygen atom of hydroperoxide is incorporated into the alkene, the other remains in an $\mathrm{OH}$ group. (Note the similarity of this scheme to the proposed molecular oxygen reaction scheme in heterogeneous epoxidation.) Direct epoxidation with oxygen is also possible by in situ generation of hydrogen peroxide. For instance, Shin and Kehoe (133) reported that reaction of $\mathrm{K}_{3} \mathrm{Co}(\mathrm{CN})_{5}$ with $\mathrm{O}_{2}$ in an acid medium results in $\mathrm{H}_{2} \mathrm{O}_{2}$ and $\mathrm{K}_{3} \mathrm{Co}(\mathrm{CN})_{6}$. They reacted the resultant hydrogen peroxide with allyl alcohol in the presence of the acid $\mathrm{H}_{2} \mathrm{WO}_{4}$ and recovered the epoxide. Note that in the process $\mathrm{Co}^{2+}$ is oxidized to $\mathrm{Co}^{3+}$.

One has to distinguish this process, which proceeds via hydrogen peroxide formation and in which Group VIII metals with different valencies play a role, from processes in which Group VIII metals and also noble metal ions catalyze the formation of the hydroperoxide, as proposed by, e.g., Rouchard and De Pauw (134).

Silver chelates and metal porphyrins of Group VIII metals catalyze reactions such as<smiles>CC(C)=CCCCCC(C)=C(C)C</smiles>

The hydroperoxide yields epoxide by autoxidations:<smiles>CC=CCC1(C)OC1(C)C[C+]C(C)=C(C)C(C)(C)OO</smiles>

The latter reactions are usually catalyzed by a Group VIIB, VB, or VIB metal. A similar reaction with cyclohexene has been reported. An extensive review of such reactions has been given by Sheldon and Kochi (135).

Apart from peroxides several other reagents are known to yield epoxide in a reaction where a complex containing a single oxygen atom reacts with an alkene. $\mathrm{Tl}^{3+}$ acetate in $50 \%(\mathrm{v} / \mathrm{v})$ aqueous acetic acid gives propylene oxide and acetone in a ratio of 1:1(136). In this reaction $\mathrm{Tl}^{3+}$ is reduced to $\mathrm{Tl}^{+}$. The ratio of propylene oxide to acetone increases with increasing polarity of the medium. 
The reaction mechanism is very similar to the Wacker reaction with $\mathbf{P d}^{2+}$ (137); however, with $\mathrm{Tl}^{3+}$, two-electron transfer generates $\mathrm{Tl}^{+}$, and the resulting positive charge causes epoxide formation:

$$
\begin{aligned}
\mathrm{Tl}^{3+}+\mathrm{C}_{2} \mathrm{H}_{4}+\mathrm{H}_{2} \mathrm{O} & \longrightarrow \mathrm{Tl}^{2+}-\mathrm{CH}_{2}-\mathrm{CH}_{2} \mathrm{OH}+\mathrm{H}^{+} \\
\mathrm{Tl}^{2+}-\mathrm{CH}_{2}-\mathrm{CH}_{2} \mathrm{OH} & \longrightarrow \mathrm{Tl}^{+}+\mathrm{C}_{2}-\mathrm{CH}_{2}+\mathrm{H}^{+}
\end{aligned}
$$

Electron-withdrawing ligands on Tl will have a beneficial effect. Similar reactions have been found for $\mathrm{Au}^{1+}-\mathrm{Au}^{3+}$ complexes (138).

Of more recent interest is the mechanism proposed for olefin epoxidation by models of cytochrome $P-450(139-142)$. Current mechanisms (139) involve a monoxygen atom $\mathrm{Mn}^{5+}$ species (Py = pyridine)

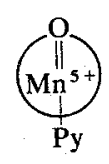

active in the epoxidation reaction, which becomes deactivated if the oxygen atom coordinated to a single metal atom in the active complex coordinates to a second metal atom:

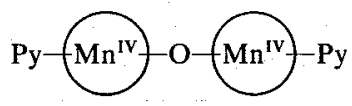

Recent work by Van der Eijk (143) demonstrates the existence of $\mathrm{a}^{\mathrm{Ag}^{3+}}$ complex containing one oxygen atom which selectively produces epoxide upon contact with an alkene. Van der Eijk proposes the silver complex:

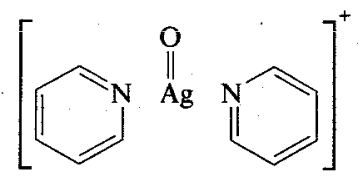

as being the active intermediate. This species can be generated electrochemically. In the transition state again a two-electron transfer occurs in which the $\mathrm{Ag}^{3+}$ ion is reduced to the $\mathrm{Ag}^{+}$ion. The main evidence stems from measurements to determine the kinetics of the reaction. Van der Eijk finds the following resuits:

$$
2 \mathrm{Ag}(\mathrm{Py})_{2}^{+}+4 \mathrm{Py} \longrightarrow \underset{\text { (red) }}{2 \mathrm{Ag}(\mathrm{Py})_{4}^{2+}+2 e}
$$

Disproportionation and reduction

$$
2 \mathrm{Ag}(\mathrm{Py})_{4}^{2+}+\mathrm{H}_{2} \mathrm{O} \rightleftarrows \mathrm{Ag}(\mathrm{Py})_{2}^{+}+\mathrm{Ag}(\mathrm{Py})_{2} \mathrm{O}^{+}+4 \mathrm{Py}+2 \mathrm{H}^{+}
$$


Epoxidation

$$
\mathrm{Ag}(\mathrm{Py})_{2} \mathrm{O}^{+}+\text {alkene } \longrightarrow \mathrm{Ag}(\mathrm{Py})_{2}^{+}+\text {epoxide }
$$

This brief survey shows that in the homogeneous phase epoxidation occurs by reaction with both, namely dioxygen as well as atomic oxygen complexes. In reactions with dioxygen, the metal catalyst becomes oxidized in the epoxidation reaction; in reactions with atomic oxygen complexes the metal catalyst becomes reduced in the epoxidation reaction.

\section{The Selective Oxygen Species}

Table III shows the free energies of combustion of ethylene and of ethylene epoxide formation. Since the rate-limiting step concerns the reaction of adsorbed oxygen with ethylene it is of interest to compare these values with the $\Delta G$ values of three reactions:

\begin{tabular}{|c|c|c|}
\hline \multicolumn{2}{|c|}{$\mathrm{O}_{2}^{\text {gas }}+\mathrm{C}_{2}^{2-}$} & $\mathrm{C}-\mathrm{C}$ \\
\hline & $T(\mathrm{~K})$ & $\Delta G(\mathrm{~kJ} / \mathrm{mol})$ \\
\hline & $\begin{array}{l}400 \\
600\end{array}$ & $\begin{array}{l}-256 \\
-248\end{array}$ \\
\hline \multicolumn{2}{|c|}{$\mathrm{O}_{\mathrm{at}}^{\mathrm{gas}}+2 \mathrm{Ag}^{\mathrm{bulk}}$} & $\mathrm{Ag}_{2} \mathrm{O}^{\text {bulk }}$ \\
\hline & $T(\mathrm{~K})$ & $\Delta G(\mathrm{~kJ} / \mathrm{mol})$ \\
\hline & $\begin{array}{l}400 \\
600\end{array}$ & $\begin{array}{l}+227 \\
+214\end{array}$ \\
\hline \multicolumn{2}{|c|}{$\mathrm{Ag}_{2}^{\mathrm{s}} \mathrm{O}$} & $2 \mathrm{Ag}^{\mathrm{s}}+\frac{1}{2} \mathrm{O}_{2}^{\mathrm{gas}}$ \\
\hline \multirow[t]{2}{*}{$T(K)$} & \multicolumn{2}{|r|}{$\Delta G(\mathrm{~kJ} / \mathrm{mol})$} \\
\hline & $0<\theta<$ & $0.9>\theta>0.5$ \\
\hline 400 & 63 & 13 \\
\hline 600 & 50 & 0 \\
\hline
\end{tabular}

These can be deduced from the data provided below each reaction. Since the differences between the heats of adsorption of ethylene and epoxide are very small, we will ignore them in the present discussion. Clearly reaction (5) is endothermic if the oxygen atom generated has to go to the gas phase. 
TABLE III

Thermodynamics of Ethylene (Ep) oxidation ${ }^{a}$

\begin{tabular}{cccc}
${ }_{2}^{1} \mathrm{O}_{2}+\mathrm{C}_{2}^{2-}$ & \multicolumn{1}{c}{$\mathrm{C}^{-} \mathrm{C}$} & $3 \mathrm{O}_{2}+\mathrm{C}_{2}^{2-}$ & $2 \mathrm{CO}_{2}+2 \mathrm{H}_{2} \mathrm{O}$ \\
\hline$T(\mathrm{~K})$ & $\Delta G(\mathrm{~kJ} / \mathrm{mol})$ & $T(\mathrm{~K})$ & $\Delta G(\mathrm{~kJ} / \mathrm{mol})$ \\
\hline 400 & -71 & 400 & -1315 \\
600 & -55 & 600 & -1310 \\
\hline
\end{tabular}

${ }^{a}$ From Ref. 118.

However, the reaction becomes energetically possible if resulting oxygen atoms adsorb onto silver. The heat of oxygen adsorption is always larger than the heat of formation of the oxide.

Formation of epoxide from oxygen adsorbed in the oxygen-coverage regime $\theta<0.5$ is barely possible. However, weakly adsorbed oxygen reacts exothermally with ethylene to give epoxide. These data explain why ethylene epoxide decomposes on a silver surface free of oxygen, but not on a surface precovered with oxygen. At high coverage the bond strength of oxygen to silver is so weak that decomposition of ethylene oxide becomes thermodynamically forbidden.

Thermodynamics does not discriminate between a rate-limiting step involving molecular oxygen and one involving atomic oxygen. However, it suggests strongly that if atomic oxygen is involved, it should be the weakly adsorbed form. We have shown that this agrees with the experimental observations.

Madix and co-workers $(144,145)$ have investigated the reactivity of oxygen atoms adsorbed to silver single-crystal faces in detail. They studied the situation where $\theta_{\mathrm{o}}<0.5$ and found that under these circumstances absorbed oxygen atoms behave in a nucleophilic manner. For instance, they react with the acidic proton of acetylene, to give $\mathrm{OH}$ and an adsorbed carbonaceous species. The reaction with acetaldehyde to acetate, as we discussed earlier, also demonstrates the nucleophilic character of this adsorbed oxygen species (114).

Cvetanovic (146) discussed the relative rates of reactions of oxygen atoms with olefins in the gas phase. He found a distinct electrophilic character of oxygen atoms in their reaction with olefins, quite different from the nucleophilic behavior of oxygen atoms at relatively low coverage on silver surfaces.

Spectroscopic work of Roberts and Joyner $(147,148)$ indicates the presence of at least three oxygen species on silver: one occurring at low coverage of low negative charge, which we identify with the nucleophilic species studied by 
Madix et al., and two other species appearing at higher coverage of less negative charge, one of which was identified as molecular oxygen. These oxygen species would behave electrophilically, as required for insertion into the electron bond of ethylen.

The presence of nucleophilic oxygen attacking $\mathrm{C}-\mathrm{H}$ bonds as well as electrophilic oxygen inserting into the $\mathrm{C}-\mathrm{C} \pi$ bond became apparent from isotope studies, with $\mathrm{C}_{2} \mathrm{D}_{4}(93,94,112)$ replacing $\mathrm{C}_{2} \mathrm{H}_{4}$.

Preadsorption of chlorine strongly suppresses total oxidation and, as Fig. 10 shows, the isotope effect found at low selectivities disappears with increasing selectivity. This shows that the rate-limiting step in the total oxidation of ethylene is $\mathrm{C}-\mathrm{H}$ bond breakage. Experiments $(149,149 a)$ with cis-substituted $d_{2}$-ethylene showed only partial retention of configuration, indicating asymmetric attack of one of the carbon atoms by electrophilic oxygen, which is necessary if an electron is donated from ethylene to an antibonding orbital of $p$ symmetry of adsorbed oxygen.

Alloying of silver with $\mathrm{Au}(108)$ reduces the selectivity of the epoxidation reaction with ethylene, but enhances the selectivity of the reaction of propylene to acrolein. It was already mentioned that $\mathrm{Cu}$ also catalyzes the oxidation of propylene to acrolein selectively, as long as the oxygen surface coverage is low. Alloying with gold strongly reduces the concentration of adsorbed oxygen. Oxygen does not adsorb on gold. One even finds an increase in the bond strength of adsorbed oxygen (107) upon dilution with gold. Clearly, the amount of weakly adsorbed oxygen decreases and we are left with strongly adsorbed oxygen alone, which reacts with the $\mathrm{C}-\mathrm{H}$ bond to give total combustion. In the case of propylene this has a favorable effect. Alloying with gold reduces the oxygen concentration and hence diminishes the chance of combustion of adsorbed acrolein. Two oxygen atoms are needed; one reacts with two $\mathrm{H}$ atoms of propylene. They will be adsorbed close to each other after dissociation of impinging oxygen.

Preadsorption of chlorine also decreases the total amount of adsorbed oxygen but in contrast to gold, adsorption of chlorine enhances the selectivity. The work of Kilty et al. (23) showed that chlorine preadsorption enhances the fraction of weakly adsorbed oxygen, the species that adsorbs with a relatively high activation energy. Their adsorption data show that a low surface coverage of $\mathrm{Cl}$ initially influences one oxygen atom per adsorbed $\mathrm{Cl}$ atom, whereas at higher chlorine coverage this ratio becomes $2: 1$.

Interestingly, analogous observations have recently been made for the suppression of $\mathrm{CO}$ chemisorption by sulfur adsorption on several metal single-crystal faces $(150,152 a)$. The results have been interpreted as an electronic effect $(153,154)$. The local density of states on surface atoms neighboring sulfur is suppressed by sulfur adsorption, which reduces the bond strength of these metal atoms with $\mathrm{CO}$. Similar effects play a role when 
chlorine is coadsorbed with oxygen. However, statistical effects resulting from the fact that two neighboring empty surface sites are required for oxygen dissociation will also play a role.

The XPS data (147), but also UPS data of oxygen adsorption to silver (155), show large changes in the electronic structure as a function of oxygen concentration.

Rovida et al. (156) have found that chlorine weakens the oxygen bond strength with silver. More recent single-crystal work $(87,157-159)$ also shows that chlorine influences the oxygen silver interaction. According to Tan et al. (87) chlorine enhances bulk transport of oxygen, thus increasing the amount of subsurface oxygen. Ayyoob and Hegde (157) and Bowker and Waugh $(158,159)$ find that chlorine itself moves to subsurface positions. Bowker and Waugh even find evidence for silver chloride formation.

The presence of chlorine may favorably influence the electronic nature of adsorbed oxygen with respect to the epoxidation reaction. Since chlorine is a strong electrophilic agent, it will induce coadsorbed oxygen to become also electrophilic. Since the partial coverage of oxygen is low at steady-state conditions, the presence of chlorine at the surface as well as at the subsurface position will change the ratio of electrophilic to nucleophilic oxygen and hence enhance the selectivity of the epoxidation reaction. Interestingly, alkali appears to enhance the bond strength of chlorine to silver (160), and may thus increase the chlorine concentration at steady-state conditions.

\section{Conclusion: The Transition State}

Significant progress has been made in explaining the uniqueness of silver as an ethylene epoxidation catalyst. We have seen that the initial selectivity of the reaction is determined by two factors: (1) the bond strength and chemical nature of the adsorbed oxygen and (2) the inability to activate the carbonhydrogen bond. The latter factor limits the catalysts to elements or components not containing transition metals, because these transition metals activate $\mathrm{C}-\mathrm{H}$ bonds. Oxygen has to dissociate, but the resulting metaloxygen bond strength should not be so high that epoxidation is excluded because of thermodynamic reasons. Silver is unique, since oxygen can dissociatively adsorb on it and at high oxygen coverage it contains weakly bound oxygen. The relatively weak bond strength of oxygen to silver thermodynamically allows formation of epoxide upon reaction with ethylene. That oxygen adsorbed to silver does activate $\mathrm{C}-\mathrm{H}$ bonds of ethylene, as is demonstrated by the lower than $100 \%$ initial selectivity. However, this reaction is slow compared to insertion of oxygen into the double bond of ethylene. 
Strongly adsorbed oxygen, the dominant species at low oxygen coverage, catalyzes the selective oxidation of propylene to acrolein. The thermodynamic requirement of weakly adsorbed oxygen is now eliminated, because water is a by-product of this reaction. A low concentration of oxygen may be beneficial because nine oxygen atoms are needed for total oxidation of propylene. The positive effect, gold alloying, on the selectivity of propylene oxidation supports this idea. By contrast, the selectivity of the ethylene epoxidation reaction decreases upon alloying with gold. The epoxidation reaction is more suppressed than the total oxidation. This agrees with the postulate that for ethylene epoxidation another oxygen species is responsible for total oxidation. The different as compared with acrolein production is that epoxidation does not involve $\mathrm{C}-\mathrm{H}$ bond breakage as the rate-limiting step.

The occasionally observed strong positive effects of coadsorption on the selectivity of the epoxidation reaction can be ascribed to reactions that suppress the formation or reaction of strongly adsorbed oxygen, leading to toal combustion of ethylene.

Clean silver surfaces yield an initial selectivity of $\sim 40 \%$. This selectivity is rather low, because of the low surface oxygen concentration which enhances the fraction of strongly adsorbed oxygen. Coadsorption of electropositive elements, e.g., alkali, may enhance the steady-state oxygen surface concentration; coadsorption of electronegative elements such as chlorine will decrease total oxygen coverage, but at the same time decrease the bond strength of adsorbed oxygen and change the chemical reactivity as a result. On the other hand, coadsorbates such as $\mathrm{CO}_{2}$ may titrate "nucleophilic" oxygen. Thus a combination of these effects tends to increase the selectivity of very clean silver surfaces. Promotion may occur only in a limited concentration regime, because at high concentration unfavorable chemical properties of coadsorbates may dominate. In addition, consecutive reactions may become enhanced as well as suppressèd by coadsorption. This has been demonstrated explicitly for alkali.

Very little work has been published in the open literature on promoted, as well as chlorine-moderated, catalysts. No data are available that demonstrate the effects of promotors on the initial selectivity of catalysts properly moderated with chlorine. Similarly, only minor study has been made of the effects of coadsorbates on the initial selectivity of such catalysts.

The study of the selective epoxidation mechanism of ethylene clearly illustrates the effect of the nature and composition of the gas phase on the composition of the surface and how modification of the surface phase affects catalysis (161).

Under practical catalytic conditions a silver oxide-chlorine surface phase is formed, in which $\mathrm{Ag}^{+}$as well as $\mathrm{Ag}^{3+}$ might occur. The chlorine as well as the oxygen atoms can occupy subsurface positions. The presence of a subsurface 
layer of electronegative atoms appears to be a prerequisite to create sites where electrophilic oxygen atoms become adsorbed. The $\mathrm{Ag}^{3+}$ cations occurring in AgO may model such sites.

The species active in homogeneous epoxidation reactions via a reaction mechanism involving a single oxygen atom are indeed metal centers, of a high positive charge $\left(\mathrm{Mn}^{5+}\right.$ or $\left.\cdot \mathrm{Ag}^{3+}\right)$, which became reduced upon reaction with the alkene. Strongly bound oxygen coordinated to more than one metal ion is not active in epoxidation.

On the AgO surface, oxygen atoms are present in bridging as well as on-top configuration. A high positive charge at the metal center or a low barrier for electron donation to the metal surface enhances the selectivity.

Because oxygen atoms of a different nature are present in the silver oxidechloride layer, the local environment of the adsorbate complex formed in the transition state will govern the course of the reaction. Subsurface chlorine or oxygen will act as electron-withdrawing ligands.

The surface phase formed under catalytic conditions differs considerably from that formed by adsorption of oxygen or ethylene under ultrahighvacuum conditions. The kinetic data indicate that ethylene is adsorbed to the silver catalyst in the elementary step, giving epoxidation.

A transition state consistent with the experimental evidence is sketched in Figs. 22a and 22c for ethylene epoxidation. The kinetic data indicate that ethylene is adsorbed to the silver catalyst in the elementary step giving epoxidation. Reaction occurs with weakly bound oxygen coordinated to a silver ion of high positive charge. Isotope experiments indicate that oxygen insertion may occur asymmetrically with only partial retention of configuration.

One of the carbon atoms is electrophilically attacked by oxygen. As a result electronic charge will be pulled away from ethylene to the silver-oxygen surface. The rate-limiting step of the nonselective reaction with ethylene is $\mathrm{C}-\mathrm{H}$ bond rupture. Strongly bound, bridging electropositive oxygen coordinated to $\mathrm{Ag}$ ions of low charge will preferentially react with the hydrogen atoms. This is sketched in Fig. $22 b$.

Even at high oxygen or chlorine surface layer concentrations, surface $\mathrm{Ag}^{\delta+}$ vacancies have to remain present in order to ensure charge neutrality of the surface-vacuum interface, and will be available for ethylene adsorption. The heat of adsorption of ethylene has been found to increase by several kilocalories/mole, if adsorption occurs next to an oxygen atom.

Since there is only partial retention of configuration, there is only limited rotation of the $\mathrm{CH}_{2}$ part of the molecule after formation of one carbonoxygen bond. On this point along the reaction coordinate, competition between epoxide formation and $\mathrm{C}-\mathrm{H}$ bond rupture, leading to total combustion, may occur. 
a

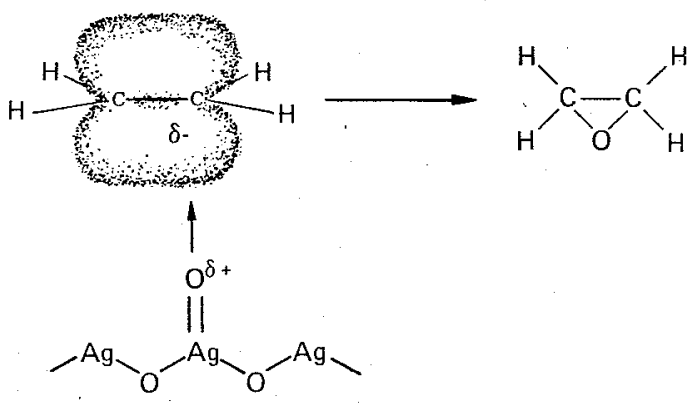

b

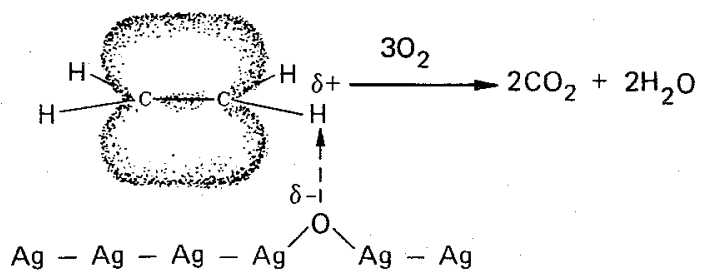

c

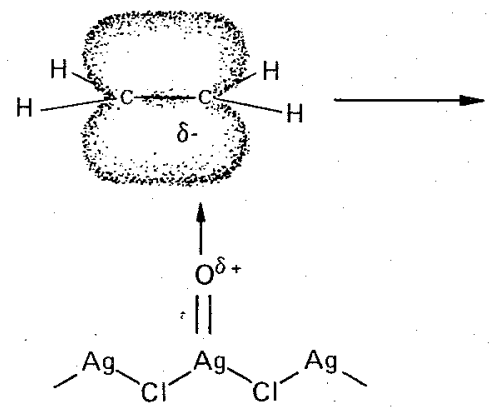<smiles>C1CO1</smiles>

FIG. 22. Schematic representation of the proposed transition state leading to epoxidation.

The effect of chlorine coadsorption may be twofold: chlorine atoms replace strongly adsorbed oxygen, which suppresses $\mathrm{C}-\mathrm{H}$ bond rupture, and chlorine adsorption weakens the bond strength of coadsorbed oxygen by withdrawal of electrons. This is schematically illustrated in Fig. 22c. According to the reaction mechanism proposed, ethylene reacts with adsorbed atomic oxygen to give epoxide. As discussed, it is unlikely, that epoxidation occurs after recombination of the oxygen atoms. Thus, in principle, there is no reason why the epoxidation selectivity should be limited to $6 / 7$. Hence, there is considerable incentive to improve current catalysts further. 
Nonselective reactions are due to the direct oxidation of ethylene and to consecutive reactions of epoxide. The conversion of epoxide also greatly depends on the state of the silver surface. Several reactions have been found. On clean silver surfaces, ethylene oxide decomposes to ethylene and adsorbed oxygen and isomerizes to acetaldehyde. These reactions are suppressed if the silver surface becomes covered with oxygen. A bifunctional reaction path involving isomerization of the epoxide by the alumina support, leading to acetaldehyde and acetaldehyde combustion catalyzed by silver, becomes important under practical conditions.

Despite the significant differences in reaction conditions prevailing in catalysis and surface science studies, the contribution of the latter work has had a considerable impact on our current views of the ethylene epoxidation reaction. We have described how knowledge gained from a wide variety of techniques has contributed to our current understanding of epoxidation catalysis. One may expect a successful future for techniques which will enhance our insight further by studies of practical systems under in situ conditions.

\section{REFERENCES}

1. Voge, H. H., and Adams, C. R., Adv. Catal. 17, 151 (1967).

Ia. Zomerdijk, J., and Hall, M., Catal. Rev. Sci. Eng. 23, 163 (1981).

1b. Dettwiler, H. R., Baiker, A., and Richarz, W., Helv. Chim. Acta 62, 1689 (1979).

1c. Bryce-Smith, D., Blues, E. T., and Griffe de Martinez, B., Chem. Ind. (London) 18, 719 (1983).

2. Law, G. H., and Chitwood, H. C., U.S. Patent 2279469 (1942).

3. Nielsen, R. P., and La Rochelle, J. H., U.S. Patent 4012425 (1977).

4. Orzechowski, A., and MacCormack, K. E., Can. J. Chem. 32, 432 (1954).

5. Twigg, G. H., Trans. Faraday Soc. 42, 284 (1946);

5a. Twigg, G. H., Proc. R. Soc. London Ser. A 188, 92 (1946).

5b. Ide, Y., Takagi, T., and Keii, T., Nippon Kagaku Zasshi 86, 1249 (1965).

5c. Woodward, J. W., Lindgren, R. G., and Corcoran, W. H., J. Catal. 25, 292 (1972).

6. Kenson, R. E., and Lapkin, M., J. Phys. Chem. 74, 1493 (1970).

6a. Prauser, G., Fischer, G., and Dialer, K., Angew. Chem. 92, 389 (1980).

7. Süptitz, H., and Kripylo, P., Chem. Tech. (Leipzig) 35, 460 (1983).

8. Grant, R. B., and Lambert, R. M., J. Catal. 93, 92 (1985).

9. Sachtler, W. M. H., Catal. Rev. 4, 27 (1970).

10. Kilty, P. A., and Sachtler, W. M. H. Catal. Rev. Sci. Eng. 10, 1 (1974).

11. Temkin, M. I., Adv. Catal. 28, 173 (1979).

12. Sachtler, W. M. H., Backx, C., and Van Santen, R. A., Catal. Rev. Sci. Eng. 23, 127 (1981);

12a. Verykios, X. E., Stein, F. P., and Coughlin, R. W., Catal. Rev. Sci. Eng. 22, 197 (1980).
13. Bowker, M., Vacuum 33, 669 (1983).

14. Voge, H. H., Proc. Int. Congr. Surf. Act., 2nd, London II, 337 (1957).

14a. Kripylo, P., Mögling, L., Ehrchen, H., Harkanyi, I, Klose, D., and Beck, L., Chem. Tech. (Leipzig) 31, 82 (1979).

15. Nault, L. G., Bolme, D. W., and Johanson, L. N., Ind. Eng. Chem. Process Des. Dev. 1, 285
(1962).

16. Belowsov, V. M., and Rubanik, M. Y., Kinet. Katal. 4, 892 (1963);

I6a. Kobayashi, M., Chem. Eng. Sci. 37, 403 (1982). 
17. Klugherz, P. D., and Harriott, P., AIChE J. 17, 856 (1971).

18. Imre, L., Ber. Bunsenges. Phys. Chem. 74, 220 (1970).

19. Herzog, W., Ber. Bunsenges. Phys. Chem. 74, 216 (1970).

20. Hayes, K. E., Can. J. Chem. 38, 2256 (1960).

21. Worbs, H., Ph.D. thesis, Technische Hochschule Breslau (1942).

21a. Broich, F., Chem. Ing. Tech. 34, 45 (1962).

21b. Meter, M. T., Ph.D. thesis, Technische Hochschule, Karlsruhe (1945).

21c. Schultze, G. L., and Thiele, H., Erdoel Kohle 5, 552 (1952).

22. Zimakov, P. V., Usp. Khim. 28, 1343 (1959).

23. Kilty, P. A., Rol, N. C., and Sachtler, W. M. H., Proc. Int. Congr. Catal., 5th Paper 64, p. 929, (1973).

24. Gerei, S. V., Kholyavenko, K. M., and Rubanik, M. Ya., Ukr. Khim. Zh. 31, 449 (1965).

25. Park, D. W., Ghazali, S., and Gau, G., Appl. Catal. 6, 175 (1983).

26. Ayame, A., Miura, H., Kimura, T., Yamaguchi, M., Kanoh, H., Miyahara, K., and Toyoshima, I., J. Res. Inst. Catal. Hokkaido Univ. 32, 49 (1984).

27. Buntin, R. B., Ph.D. thesis, Purdue University, West Lafayette, Ind., 1961.

27a. Metcalf, P. L., and Harriott, P., Ind. Eng. Chem. Process Des. Dev. 11, 478 (1972).

27b. Ostrovskii, V. E., Kul'kowa, N. V., Lopatin, V. L., and Temkin, M. I., Kinet. Katal. 3, 189 (1962).

27c. Akimoto, M., and Echigoya, E., Bull. Chem. Soc. Jpn. 51, 3061 (1978).

28. Force, E. L., and Bell, A. T., J. Catal. 38, 440 (1975).

28a. Force, E. L., and Bell, A. T., J. Catal. 40, 356 (1975).

28b. Force, E. L., and Bell, A. T., J. Catal. 44, 175 (1976).

29. Campbell, C. T., and Paffett, M. T., Surf. Sci. 139, 396 (1984).

30. Campbell, C. T., and Paffett, M. T., Surf. Sci. 143, 517 (1984).

31. Grant, R. B., and Lambert, R. M., J. Catal. 93, 92 (1985).

32. Backx, C., de Groot, C. P. M., and Biloen, P., Surf. Sci. 104, 300 (1981).

33. Clarkson, R. B., and Cirillo, Jr., A. C., J. Vac. Sci. Technol. 9, 1073 (1972).

34. Clarkson, R. B., and Cirillo, Jr., A. C., J. Catal. 33, 392 (1974).

35. Kilty, P. A., Rol, N. C., and Sachtler, W. M. H., Proc. Int. Congr. Catal., 5 th 929 (1972).

36. Barteau, M. A., and Madix, R. J., Surf. Sci. 97, 101 (1980).

37. Barteau, M. A., Bowker, M., and Madix, R. J., Surf. Sci. 94, 303 (1980).

38. Bowker, M., Barteau, M. A., and Madix, R. J.s Surf. Sci. 92, 528 (1980).

39. Au, C. T., Singh-Boparai, S., Roberts, M. W., and Joyner, R. W., J. Chem. Soc. Faraday Trans. I 79, 1779 (1983).

40. Stuve, E. M., Madix, R. J., and Sexton, B. A., Surf. Sci. 111, 11 (1981).

41. Prince, K. C., and Bradshaw, A. M., Surf. Sci. 126, 49 (1983).

42. Spitzer, A., and Lüth, M., Surf. Sci. 118, 121, 136 (1982).

43. Sexton, B. A., and Madix, R. J., Chem. Phys. Lett. 76, 294 (1980).

44. Selmani, A., Sichel, J. M., and Salahub, D. R., Surf. Sci. 157, 208 (1985).

45. Puschmann, A., Prince, K. C., Haase, J., and Bradshaw, A. M., Int. Conf. Study Surf. Berkeley July (1984).

46. Rao, C.N.R., Kamath, $P_{\text {. }} \mathrm{V}_{\text {c; }}$ and Yashonath, $S_{\mathrm{y}}$ Chem. Phys. Lett. 88, 13 (1982).

47. Bange, K., Madey, T. E., and Sas, J. K., Chem. Phys. Lett. 113, 56 (1985).

48. Grant, R. B., and Lambert, R. M., J. Chem. Soc. Chem. Commun. 58 (1983).

49. Grant, R. B., and Lambert, R. M., Surf. Sci. 146, 256 (1984).

50. Fraser, W. A., Florio, J. V., Delgass, W. N., and Robertson, W. D., Surf. Sci. 36, 661 (1973).

51. Campbell, C. T., Surf. Sci. 157, 43 (1985).

52. Behm, J., and Brundle, C. R., in preparation.

53. Ekern, R. J., and Czanderna, W. A., J. Catal. 46, 109 (1977). 
54. Evans, S., Evans, E. L., Parry, D. E., Tricker, M. J., Walters, M. J., and Thomas, J. M., Faraday Discuss. Chem. Soc. 58, 97 (1974).

55. Eickmans, J., Otto, A., and Goldmann, A., Surf. Sci. 149, 293 (1985).

56. Engelhardt, H. A., and Menzel, D., Surf. Sci. 57, 591 (1976).

57. Albers, H., Van der Wal, W. J. J., Gijzeman, O. L. J., and Bootsma, G. A., Surf. Sci. 77, 1 (1978).

58. Bradshaw, A. M., Engelhardt, H. A., and Menzel, D., Ber. Bunsenges. Phys. Chem. 76, 500 (1972).

59. Engelhardt, H. A., Bradshaw, A. M., and Menzel, D., Surf. Sci. 40, 410 (1973).

60. Rovida, G., and Pratesi, F., Surf. Sci. 52, 542 (1975).

61. Rovida, G., Ferroni, E., Maglietta, M., and Pratesi, F., "Adsorption-Desorption Phenomena" (F. Ricca, ed.), p. 417. Academic Press, 1972.

62. Rovida, G., Pratesi, F., Maglietta, M., and Ferroni, E., J. Vac. Sci. Technol. 9, 796 (1972).

63. Heiland, W., Iberl, F., Taglauer, E., and Menzel, D., Surf. Sci. 53, 383 (1975).

64. Rösch, N., and Menzel, D., Chem. Phys. 13, 243 (1976).

65. Martin, R. L., and Hay, P. J., Surf. Sci. 130, L283 (1983).

66. Bange, K., Madey, T. E., and Sas, J. K., Chem. Phys. Lett. 113, 56.(1985).

67. Lin, J.-H.,., and Garrison, B. J., J. Chem. Phys. 80, 2904 (1984).

68. Felter, T. E., Weinberg, W. H., Lastushkina, G. Ya., Boronin, A. I., Zhdan, P. A., Boreskov, G. K., and Hrbek, J., Surf. Sci. 118, 369 (1982).

69. Benndorf, C., Frank, M., and Thieme, F., Surf. Sci. 128, 417 (1983).

70. Rovida, G., Pratesi, F., Maglietta, M., and Ferroni, E., Surf. Sci. 43, 230 (1974).

71. Bowker, M., Surf. Sci. 100, L472 (1980).

72. Briggs, D., Marbrow, R. A., and Lambert, R. M., Surf. Sci. 65, 314 (1977).

73. Marbrow, R. A., and Lambert, R. M., Surf. Sci. 61, 317 (1976).

74. Garfunkel, E. L., Ding, X., Dong, G., Yang, S., Hon, X., and Wang, X., Surf. Sci. 164, 511 (1985).

75. Kitson, M., and Lambert, R. M., Surf. Sci. 109, 60 (1981).

76. Goddard, P. J., and Lambert, R. M., Surf. Sci. 107, 519 (1981).

77: Campbell, C. T., J. Phys. Chem. 89, 5789 (1985).

78. Grant, R. B., and Lambert, R. M., Langmuir 1, 29-33 (1985).

79. Parker, S. D., and Rhead, G. E., Surf. Sci. 167, 271-284 (1986).

80. Orzechowski, A., and MacCormack, K. E., Can. J. Chem. 32, 388, 415, 443 (1954).

81. Kagawa, S., Iwamoto, M., Mori, H., and Seiyama, T., J. Phys. Chem 85, 434 (1981);

81a. Kagawa, S., Tokunaga, H., and Seiyama, T., Kogyo Kagaku Zasshi 71, 775 (1968).

82. Kagawa, S., Iwamoto, M., and Seiyama, T., Chem. Tech. 11, 426 (1981).

83. Benton, A. F., and Drake, L. C., J. Am. Chem. Soc. 54, 2186 (1932).

84. Otto, E. M., J. Electrochem. Soc. 113, 643 (1966).

85. Campbell, C. T., and Paffett, M. T., Appl. Surf. Sci. 19, 28 (1984).

86. Campbell, C. T., J. Catal. 99, 28 (1986).

87. Tan, S. A., Grant, R. B., and Lambert, R. M., J. Catal. 100, 383 (1986).

88. Akella, L. M., and Lee, H. H., J. Catal. 86, 465 (1984).

89. Backx, C., Moolhuysen, J., Geenen, P., and Van Santen, R. A., J. Catal. 72, 364 (1981);

$89 a$. Boreskov, G. K., Gruver, V. Sh., Pankrat'er, Yu. D., Turkov, V. M., and Khasin, A. V., Dokl. Akad. Nauk. SSSR 215, 359 (1974).

89b. Parfenov, A. N., Avetisov, A. K., and Gel'bshtein, A. I., Dokl. Akad. Nauk. SSSR 272, 1168 (1983).

89c. Sato, N., and Seo, M., J. Catal. 24, 224 (1972).

89d. Haul, R., Neubauer, G., Fischer, D., Hoge, D., and Zeeck, W., Proc. Int. Conf. Catal., Sth, Berlin III, 265 (1984). 
90. Grant, R. B., and Lambert, R. M., J. Chem. Soc. Chem. Comm. 662 (1983).

91. Jansen, M. M. P., Moolhuysen, J., and Sachtler, W. M. H., Surf. Sci. 33, 624 (1972).

92. Stoukides, M., and Vayenas, C. G., J. Catal. 70, 137 (1981).

93. Van Santen, R. A., Moolhuysen, J., and Sachtler, W. M. H., J. Catal. 65, 478 (1980).

94. Grant, R. B., and Lambert, R. M., J. Catal. 92, 364 (1985).

95. Krause, A., Rozn. Chem. Ann. Soc. Chim. Pol. 37, 1051 (1963).

96. Kobayashi, M., in "Catalysis under Transient Conditions," p. 209. American Chem. Soc., Washington, D.C., 1982.

97. Bulushev, D. A., Mater. Vses. Nauchn. Stud. Konf. "Stud. Nauchno-Tekh. Prog.": Khim. 21st, 38. (L. D. Likanskaya ed.). Novosib. Gas Univ., Novosibirsk, USSR.

98. Kripylo, P., Mögling, L., and Klose, D., Chem. Tech. (Leipzig) 35, 87 (1983).

99. Beck, L., Kripylo, P., Thätner, R., and Geyer, R., Chem. Tech. (Leipzig) 31, 629 (1979).

100. Kharson, M. S., Mamedor, A. Kh., and Kiperman, S. L., Kinet. Katal., 25, 107 (1984).

101. Spath, H. T., Rev. Port. Quim. 19, 24 (1977).

101a. Spath, H. T., Tomazic, G. S., Wurm, H., and Tokar, C., J. Catal. 26, 18 (1972). .

102. Margolis, L. Ya., Adv. Catal. 14, 429 (1963).

103. Moss, R. L., and Thomas, H., J. Catal. 8, 151 (1967).

104. Moss, R. L., and Thomas, D. H., J. Catal. 8, 162 (1967).

105. Cormack, D., Thomas, D. H., and Moss, R. L., J. Catal. 32, 492 (1974).

106. Mehrotra, P., and Verykios, X. E., J. Catal. 88, 409 (1984).

107. Flank, W. H., and Beachell, H. C., J. Catal. 8, 316 (1967).

108. Geenen, P. V., Boss, H. J., and Pott, G. T., J. Catal. 77, 499 (1982).

109. Callahan, J. L., and Graselli, R. K., AIChE J.9, 755 (1963).

110. Mazzocchia, C., Di Renzo, F., Morazzoni, F., and Figueras, F., Actas Simp. Iberoam. Catal. 9th 2, 868 (1984). Soc. Iberoam. Catal. Lisbon, Port.

111. Verma, A., and Kaliagume, S., J. Catal. 30, 430 (1973).

112. Cant, N. W., and Hall, W. R., J. Catal. 52, 81 (1978).

113. Kanno, T., and Kobayashi, M., Proc. Int. Catal. Conf., 8th, Berlin III, 277 ff. (1984).

113a. Backx, C., De Groot, C. P. M., Biloen, P., and Sachtler, W. M. H., Surf. Sci. 128, 81 (1983).

114. Barteau, M. A., Bowker, M., and Madix, R. J., J. Catal. 67, 118 (1981);

114a. Sault, A. G., and Madix, R. J., Surf. Sci., 172, 598 (1986).

115. Stoukides, M., and Vayenas, C. G., J. Catal. 64, 18 (1980).

116. Kanoh, M., Nichimura, T., and Ayame, A. J., J. Catal. 57, 372 (1979).

117. Van Santen, R. A., and De Groot, C. P. M., J. Catal. 98, 530 (1986).

118. Czanderna, A. W., J. Vac. Sci. Technol. 14, 408 (1977).

119. Prince, K. C., Paolucci, G., Bradshaw, A. M., Horn, K., and Mariani, C., Vacuum 33, 867 (1983).

120. Haul, R., Hoge, D., Neubauer, G., and Zeeck, U., Surf. Sci. 122, L662 (1982).

121. Mikami, J., Satoh, S., and Kobayashi, H., J. Catal. 18, 265 (1970).

122. Tanaka, S., and Yamashina, T., J. Catal. 40, 140 (1972).

123. Kagawa, S., Kono K., Futata, H., and Seiyama, T., Kogyo Kagaku Zasshi 74, 819 (1971).

124. Clarkson, R. B., and Cirillo, A. C., J. Catal. 33, 392 (1974).

125. Camphell, C. T., Surf. Sci. 143, 517 (1984).

126. Backx, C., De Groot, C. P. M., and Biloen, P., Surf. Sci. 104, 300 (1981).

127. Backx, C., De Groot, C. P. M., Biloen, P., and Sachtler, W. M. H., Surf. Sci. 128, 81 (1983).

128. Bowker, M., Surf. Sci. 155, L276 (1985).

129. Van Santen, R. A., and De Groot, C. P. M., J. Catal. 98, 530 (1986).

130. Sandler, Y. L., and Durigon, D. D., J. Phys. Chem. 69, 4201 (1965).

131. Emeis, C. A., and De Wit, H., unpublished results.

132. Sheldon, R. A., and Kochi, J. K., Adv. Catal. 25, 272 (1976). 
133. Shin, K., and Kehoe, L., J. Org. Chem. 36, 2717 (1971).

134. Rouchard, J., and De Pauw, M., J. Catal. 34, 175 (1974).

135. Sheldon, R. A., and Kochi, J. K., Oxid. Combust. Rev. 5, 135 (1973).

136. McKillop, A., and Taylor, E. C., Adv. Organomet. Chem. 11, 147 (1973).

137. Henry, P. H., Adv. Chem. Ser. 70, 126 (1968).

138. Hüttel, R., Reinheimer, H., and Nowah, K., Chem. Ber. 101, 3761 (1968).

139. Razenberg, J. A. S. J., Nolte, R. J. M., and Drenth, W., Tetrahedron Lett. 25, 789 (1985).

140. Groves, J. T., and Nemo, Th., J. Am. Chem. Soc. 105, 5786 (1983).

141. Collman, J. P., Braumann, J. I., Meunier, B., Hayashi, T., Kodadek, T., and Raybuck, S. A., J. Am. Chem. Soc. 107, 2000 (1985).

142. Smegal, J. A., and Hill, C. L., J. Am. Chem. Soc. 105, 3515 (1983).

143. Van der Eijk, J., unpublished results.

144. Canning, N. D. S., and Madix, R. J., J. Phys. Chem. 88, 2437 (1984).

145. Barteau, M. A., and Madix, R. J., Surf. Sci. 115, 355 (1982).

146. Cvetanovic R. J., Can. J. Chem. 38, 1678 (1960).

147. Joyner, R. W., and Roberts, M. W., Chem. Phys. Lett. 60, 459 (1979).

148. Roberts, M. W., Adv. Catal. 29, 55 (1980).

149. Egashira, M., Kuczkowski, R. L., and Cant, N. W., J. Catal. 65, 297 (1980);

149a. Richey, W. F., J. Phys. Chem. 76, 213 (1972).

150. Trenary, M., Uram, K. J., and Yates, J. T., Surf. Sci. 157, 512 (1985).

151. Benziger, J., and Madix, R. J., Surf. Sci.94, 119 (1980).

152. Jorgensen, S. W., and Madix, R. J., Surf. Sci. 163, 19 (1985).

152a. Goodman, D. W., Acc. Chem. Res. 17, 194 (1984).

153. Joyner, R. W., Pendry, J. B., Saldin, D. K., and Tennison, S. R., Surf. Sci. 138, 84 (1984).

154. Van Santen, R. A., Faraday Symp. Chem. Soc. 21, Paper 1 (1986).

155. Au, C. T., Singh-Bopara, S., Roberts, M. W., and Joyner, R. W., J. Chem. Soc. Faraday Trans. I 79, 1779 (1981).

156. Rovida, G., Pratesi, F., and Ferronic, E., J. Catal. 41, 140 (1976).

157. Ayyoob, M., and Hegde, M. S., J. Catal. 97, 516 (1986).

158. Bowker, M., and Waugh, K. C., Surf. Sci. 134, 639 (1983).

159. Bowker, M., and Waugh, K. C., Surf. Sci. 155, 1 (1984).

160. Kitson, M., and Lambert, R. M., Surf. Sci. 110, 205 (1981).

161. Parravano, G., Ind. Eng. Chem. 58, 45 (1966). 